NBER WORKING PAPER SERIES

\title{
HETEROGENEITY IN COST-SHARING AND COST-SENSITIVITY, AND THE ROLE OF THE PRESCRIBING PHYSICIAN
}

\author{
Mariana Carrera \\ Dana Goldman \\ Geoffrey Joyce \\ Working Paper 19186 \\ http://www.nber.org/papers/w19186 \\ NATIONAL BUREAU OF ECONOMIC RESEARCH \\ 1050 Massachusetts Avenue \\ Cambridge, MA 02138 \\ June 2013
}

We are grateful to David Card, Stefano DellaVigna, William Dow, Enrico Moretti, Neeraj Sood, and to seminar participants at RAND, ASHEcon, U.C. Berkeley, U.S.C., Cornell, University of Pittsburgh, Case Western Reserve, and Indiana University- Purdue University. All errors are our own. Research reported in this working paper was supported by the National Institutes of Health under award number R01AG029514. The content is solely the responsibility of the authors and does not necessarily represent the official views of the National Institutes of Health or the National Bureau of Economic Research.

NBER working papers are circulated for discussion and comment purposes. They have not been peerreviewed or been subject to the review by the NBER Board of Directors that accompanies official NBER publications.

(C) 2013 by Mariana Carrera, Dana Goldman, and Geoffrey Joyce. All rights reserved. Short sections of text, not to exceed two paragraphs, may be quoted without explicit permission provided that full credit, including $(\mathrm{C}$ notice, is given to the source. 
Heterogeneity in Cost-Sharing and Cost-Sensitivity, and the Role of the Prescribing Physician Mariana Carrera, Dana Goldman, and Geoffrey Joyce

NBER Working Paper No. 19186

June 2013

JEL No. I1

\begin{abstract}
In this paper, we use individual level data on purchases of one of the most prescribed categories of drugs (cholesterol-lowering statins) to study the responses of physicians and patients to variation in the cost of drugs. In a sample of first-time statin prescriptions to employees from a group of Fortune 500 firms, we find that copay variation across plans has a relatively small effect on the choice of drug, and this effect does not vary with patient income. After the highly-publicized expiration of the patent for Zocor (simvastatin), however, prescriptions for this drug increased substantially, especially for lower-income patients. Our analysis suggests that physicians can perceive the adherence elasticity of their patients and adjust their initial prescriptions accordingly, but only in response to a large and universal price change. Using prescriber identifiers, we present suggestive evidence that physicians learn about a patient's price sensitivity through their own experience of prescribing to that patient.

Mariana Carrera

Case Western Reserve University

2452 Kenilworth Rd.

Cleveland Heights, OH 44106

mpc67@case.edu

Dana Goldman

Schaeffer Center for Health Policy and Economics

University of Southern California

3335 S. Figueroa St, Unit A

Los Angeles, CA 90089-7273

and NBER

dana.goldman@usc.edu

미미eoffrey Joyce

एس山س山S

एس山ा山University of Southern California

एسmய13335 S. Figueroa St., Unit A

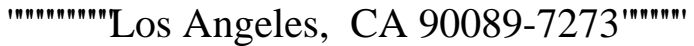

एسmlllland NBER

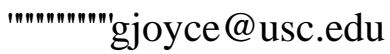




\section{Introduction}

Over the past two decades, insurers have sought to rein in rising drug costs by increasing patient cost-sharing and adopting incentive-based benefit structures. Tiered formularies, which use multiple copay levels ("tiers") to encourage choice of generic or certain brand drugs, have become nearly ubiquitous in both employer-sponsored and Medicare Part D plans. ${ }^{1}$ Relative to simpler benefit structures with a fixed copay (out-of-pocket cost) for all covered drugs, tiered formularies have been found to reduce overall drug expenditures while shifting costs heavily towards patients. ${ }^{2}$ Stud- $^{-}$ ies have cautioned, however, that higher cost-sharing hurts utilization rates of important chronic medications, causing savings on pharmaceuticals to be partially offset by increased medical costs [Chandra et al., 2010, Gaynor et al., 2007].

Little attention has been paid to the role of physicians, who can, in theory, mitigate the harmful effects of cost-sharing through cost-sensitive prescribing. Tiered formularies operate on the assumption that cost-sensitive patients can choose low-tier drugs, but prescription drugs cannot, by definition, be purchased at will. Instead, patients rely on physicians to write a prescription, wherein three interacting problems emerge: First, the physician may not know the price-sensitivity of a given patient, which will determine her adherence decision. ${ }^{3}$ Second, physicians may put too little weight on a patient's costs, relative to her level of price-sensitivity. Third, with a variety of multi-tiered formularies operating in any given geographic market, most physicians don't observe a patient's array of copayments [Shrank et al., 2005, Khan et al., 2008]. In the prescribing of chronic, preventative drugs, these asymmetric information problems can have both health and welfare consequences. ${ }^{4}$ Prescribing a more expensive drug than necessary raises the risk of poor adherence, which is estimated to cause $\$ 100$ billion in excess hospitalizations and more than 125,000 extra deaths each year [NEHI, 2009].

In this paper, we study how initial prescriptions respond to copay changes in plan formularies, and how these responses vary with patient income. We focus on the most prescribed class of drugs

\footnotetext{
${ }^{1}$ In 2010, benefit designs with 3 or more tiers applied to 78 percent of privately insured workers and over 85 percent of Medicare Part D beneficiaries. In 2000, only 29 percent of privately insured workers faced these benefit designs [Kaiser Family Foundation, 2010, Hargrave et al., 2010].

${ }^{2}$ See Goldman et al. [2007] for a review of this literature.

${ }^{3}$ For clarity, we use "he" for the physician and "she" for the patient throughout the paper.

${ }^{4}$ This results from the fact that physicians can only prescribe one drug out of a given choice set, and switching costs are large (see evidence in Appendix.)
} 
in the U.S., HMG-CoA reductase inhibitors (statins). Statins reduce blood levels of low-density lipoprotein cholesterol (LDL), and are proven to reduce the risk of coronary heart disease and heart attacks. ${ }^{5}$ Beyond its economic importance as the largest class in U.S. sales until 2007 and the third largest class today, ${ }^{6}$ the statin drug class is arguably the one where we are most likely to find sizeable copay effects on prescribing. It contains five drugs that are highly substitutable for the majority of users, in terms of both their effects on cholesterol and side effects. ${ }^{7}$ Furthermore, statins are expensive and meant to be used indefinitely, so a reasonable agent for a patient ought to consider her costs. In our sample, the average yearly out-of-pocket cost for an adherent statin user is $\$ 216$, but only $49 \%$ of starting patients are adherent over the first year.

The first goal of this paper is to estimate how copay variation across plans affects drug choice for non-elderly patients receiving a first statin prescription between 2005 and mid-2006. In this period, the five drugs in the choice set were all patented brand drugs that varied in their tier levels across plans, and we find that the effect of this type of copay variation is modest: When the most prescribed statin, Lipitor, costs $\$ 10$ less per month than the second-most prescribed statin, Zocor, Lipitor's prescribing share is only 4 percentage points greater than when their copays are equal.

Our second goal is to determine whether the price responsiveness of prescribing is constrained by the difficulty of observing patients' plan formularies. To do so, we study an event that caused a copay shock that was highly publicized and highly correlated across plans: the patent expiration of Zocor, the first among these five similar drugs, in June 2006. Since generic drugs are always assigned the lowest copay tier in incentive-based formularies, Zocor's patent expiration brought about a $\$ 12.50$ drop in its average monthly copay among employer-insured patients [Kaiser Family Foundation, 2010]. The resulting shift in initial prescriptions was approximately twice as large as would be predicted based on the cross-sectional estimates of copay effects on prescribing. We argue that this indicates physicians respond more strongly to expected copays than to actual copays.

The critical assumption underlying our approach is that patient preferences- or any unobserved characteristics that make certain statins a better choice- are uncorrelated with the copayments set by patients' insurers. We investigate this assumption with an analysis of how patient

\footnotetext{
${ }^{5}$ Grundy et al. [2004] review recent long-term trials and their implications for recommended treatment guidelines.

${ }^{6}$ Source: IMS Health press release: "Top Therapeutic Classes by U.S. Spending"

${ }^{7} 84 \%$ of new statin patients receive a drug that is expected to reduce their LDL cholesterol by $34 \%$ to $52 \%$, and therapeutic differences between the five drugs in this choice set are minimal [Rosenson, 2012].
} 
adherence responds to cross-sectional variation in copays: if plans have private information on patient preferences and set their copays accordingly, then cross-sectional estimates of copay elasticity would differ from estimates based on plan-specific copay changes over time. The results support our identifying assumption, and also demonstrate the large difference in price-sensitivity of low-salary and high-salary patients.

Other recent studies, which we review in a later section, have examined how doctors take into account the costs faced by their patients. ${ }^{8}$ Our work departs from this literature in two ways. First, we differentiate between two types of cost variation, one of which is much easier for physicians to observe. While others have suggested that the difficulty of observing prices limits doctors' ability to act as agents for their patients [Shrank et al., 2005, Iizuka, 2012], we are the first to estimate the magnitude and consequences of this information problem.

Second, our ability to observe patient income allows us to make several novel contributions. Most previous studies of cost-sharing focus either on employer-sponsored plans without income data (e.g. Goldman et al. [2004] and Gaynor et al. [2007]), or on low-income populations with government-subsidized insurance (e.g. Chandra et al. [2012] and Tamblyn et al. [2001]). Our setting allows us to hold plan costs and policies constant in estimating how patient price elasticities vary with income, and we find a striking difference.

Given that income is an important determinant of the cost sensitivity of adherence, it is important to understand how prescribers respond. The extent to which they are able to identify lowerincome patients, and choose a low-cost drug for them, reduces the scope of adverse consequences of high cost-sharing for other drugs. Since patient costs are typically unobserved by physicians, however, their ability to prescribe cost-effectively depends partly on how well a patient knows her formulary and communicates with her physician. Since income correlates positively with education as well as measures of patient engagement [Hibbard and Cunningham, 2008], lower-income patients may actually be less likely to obtain prescriptions for low-tier brand drugs.

Thus, the third goal of this paper is to test for different price responses by patient income. We find that lower-income patients do not receive more cost-sensitive prescriptions when the choice set contains only patented brand drugs. They do, however, experience a greater increase in the prescribing of a drug when it "goes generic." This suggests that despite being generally unaware

\footnotetext{
${ }^{8}$ Iizuka [2012], Lundin [2000], Dickstein [2012], and Limbrock [2011] are some of the most relevant works.
} 
of their patients' copays, physicians know that generic drugs are cheaper, and use this knowledge to provide lower-income patients with more affordable drugs. Thus, beyond simply reducing the cost of one drug, the existence of a known off-patent drug improves the efficiency with which physicians match patients to drugs. This finding is particularly timely, as the Supreme Court investigates the legality of "pay-to-delay" agreements between patent-holding brand owners and generic manufacturers of the same drug. ${ }^{9}$ Our results suggest that the first patent expiration in a class of chronic drugs has the potential to reduce disparity in health outcomes across socio-economic groups by improving the health and welfare of lower income populations.

To test whether our results are driven by low-salary patients or their pharmacists specifically requesting generic Zocor, in lieu of physicians responding to patient income, we look for evidence of prescriber learning through past interactions with a specific patient. We find that low-salary patients are significantly more likely to receive a prescription for generic Zocor if they have received other prescriptions in the past from the current prescriber, holding constant their past prescriptions from any prescriber.

Combining the results from our prescribing and adherence analyses, we are able to estimate the health costs of physicians' imperfect information and agency. We find that the average adherence rate of low-salary patients would increase by around 4 percentage points, reducing the gap in adherence of low and high salary patients by approximately one-third (from 11.4 to 7.7 percentage points), if all patients were prescribed the lowest-cost drug in their choice set. While the adherence of high salary patients would not be significantly affected, both low and high salary patients would pay, on average, $\$ 8-\$ 9$ less per monthly prescription. Via a simulation, we find that providing physicians with perfect information on patient copays would only achieve about $15 \%$ of these gains. Thus, we conclude that while the difficulty of observing copays is indeed an obstacle to cost-sensitive prescribing, it is not primarily responsible for the fact that prescriptions to low-salary patients are insufficiently responsive to their costs.

This paper proceeds as follows. Section 2 discusses the institutional setting and relevant literatures. Section 3 describes the data, Section 4 presents our conceptual framework, and Section 5 contains our empirical framework and results. Section 6 discusses robustness, and Section 7 concludes.

\footnotetext{
${ }^{9}$ Federal Trade Commission v. Actavis, No. 12-416.
} 


\section{Institutional Background}

In this section, we summarize the roles and incentives of each player in the prescribing and dispensing of prescription drugs, and relevant research on their behavior. We then describe the statin drug class and the patent expiration of Zocor (simvastatin) and Pravachol (pravastatin) in 2006.

Since our data consist of filled (purchased) rather than written prescriptions, what we call the "physician prescribing decision" is the net output of a series of action that begin and end with the physician. Since the physician must approve any prescription switch suggested by any other party, pharmacist and patient requests can be understood as a mechanism through which the physician learns about the copays, copay sensitivity, and drug preferences of a given patient.

\subsection{The Health Plan and Formulary}

In setting levels of patient cost-sharing and procedures for obtaining prescription drugs, health plans can influence their beneficiaries' utilization rates. While facing double-digit annual growth of drug expenditures from 1995 to 2004, many insurers implemented aggressive cost-cutting strategies including tiered or "incentive-based" formularies either on their own or through a pharmacy benefit manager (PBM). This rapid shift has drawn substantial research attention to the effects of patient cost-sharing, with most studies finding that cost-sharing in general, and tiered formularies in particular, reduce drug utilization and expenditures. ${ }^{10}$.

Apart from drug formularies, insurers and PBMs have other ways of influencing prescribing: they can make contracts with physicians that disincentivize repeat visits from patients, effectively encouraging the prescription of drugs that patients are less likely to request changing [Dickstein, 2012], or they can implement various restrictive policies termed "utilization management strategies." For example, step therapy requires a patient to have tried a low-cost (Tier 1 or Tier 2) drug prior to purchasing other more costly drugs. Prior authorization requires the prescribing physician to document a patient's need for a specific medication prior to its approval for coverage. Limbrock [2011] estimates the average effect of these unobserved insurer strategies through the additional increase in prescribing probability of each plan's "preferred" (lowest tier) drugs beyond the effect

\footnotetext{
${ }^{10} \mathrm{~A} 10 \%$ increase in the price faced by the patient reduces drug spending by $2 \%$ to $6 \%$, depending on drug class and patient health conditions, and the utilization change is largely driven by adherence rather than starting and stopping rates. [Goldman et al., 2007]
} 
explained by the copay difference. He finds that these effects are stronger in HMO plans (equivalent to a $\$ 8.57$ copay discount) than in other plans ( $\$ 4.85$ copay discount). These strategies can be used to encourage prescribing of either Tier 1 (generic) or Tier 2 (preferred brand) drugs.

Are insurers reducing their current drug expenditures at the expense of future medical costs? Since chronic prescription drugs are an expensive investment in long-term patient health, insurers may not pursue efficient levels of their use if another insurer- or Medicare- is likely to reap the gains of the health improvements. Cebul et al. [2011] and Fang and Gavazza [2011] provide theoretical reasons for dynamic inefficiency in preventive care investments; Herring [2010] presents empirical evidence that firms' expectations of employee turnover have a negative effect on their beneficiaries' utilization of preventive services. ${ }^{11}$ In the short-term, Chandra et al. [2010] find that $20 \%$ of the savings due to increased copayments for office visits and prescription drugs is offset by an increase in hospital charges in an elderly population, and Gaynor et al. [2007] find a 35\% offset rate for drug copayments in a non-elderly population.

\subsection{The Physician}

A prescription must indicate a specific drug molecule, either by brand name or molecular (generic) name. For this reason, physicians have the "first move" in the process determining an individual's first fill. However, they may respond to patient requests for a certain drug prior to writing the prescription. While physicians who work exclusively for one managed care organization (for example, Kaiser in California) may face pressure or incentives from their employer to prescribe cost-effectively, no such incentives are present in the typical physician practice. Nonetheless, the vast majority of physicians agree, in surveys, that "When choosing between equally effective and safe medications, it is important to prescribe the drug that minimizes patients' out-of-pocket costs" [Shrank et al., 2005, Khan et al., 2008]. To our knowledge, no studies have asked physicians whether they would prescribe a slightly inferior medication if it would greatly reduce a patient's costs.

There is a large literature on physician agency in the choice of prescription drugs (Iizuka [2012], Lundin [2000], Lu (2011), Ching (2010), Liu et al. (2009)), primarily focused on non-US

\footnotetext{
${ }^{11}$ Very large firms, however, are typically self-insured, and often continue to cover their employees as retirees (Kaiser Family Foundation [2007]). The firms in our study fall into this category. Their stronger incentives to promote adherence to chronic drugs may explain why many plans in our sample offer more generous pharmaceutical benefits than commercially insured plans on average.
} 
countries where there is greater variation in physicians' financial incentives to prescribe drugs, but less variation in cost-sharing across patients. These studies find that physicians respond to financial motives to prescribe more expensive drugs, but moreso when treating insured versus uninsured patients [Lu (2011) and Lundin [2000]], or elderly patients in a setting where there they face no marginal cost for prescriptions lizuka [2007]. In settings where they face no direct financial motives (like the U.S.), physicians are also found to prescribe more expensive drugs when patients face lower levels of cost-sharing, indicating possible tension between their consideration of patient costs and their loyalty to certain drug manufacturers [Lundin, 2000]. There is evidence that pharmaceutical marketing to physicians affects prescribing [Gönül et al., 2005, Venkataraman and Stremersch, 2007, 09] and significant debate about whether such marketing is harmful to patients. ${ }^{12}$ Gonzalez et al. [2008] find evidence in the U.K. that physicians are sensitive to pharmaceutical detailing, shifting their prescribing towards other on-patent drugs when a major antidepressant (Prozac) loses its patent. In the U.K., however, an off-patent molecule offers no cost savings to patients, who pay a flat out-of-pocket cost for all drugs.

There is also evidence of habit formation in prescribing, which could lead to inefficient outcomes even in the absence of monetary incentives (Frank and Zeckhauser [2007], Taub et al. [2011]). Studies have found that physicians adopt practice styles suited to their typical patient; for example, Hellerstein [1998] finds that physicians with a larger share of patients in HMOs prescribe more generic drugs to all of their patients, including those not in HMOs. Virabhak and Shinogle [2005] find evidence of spillovers of Medicaid Preferred Drug Lists (PDLs) on non-Medicaid patients. ${ }^{13}$ Joyce et al. [2011] however, find that individual physicians do not rely on the same drug for all patients: in drug classes with a large number of "me-too" drugs, most physicians use at least half of these drugs as initial prescriptions.

Iizuka [2012] examines the choice to prescribe a brand vs. generic version of a drug in Japan, where some physicians work in "vertically integrated" (VI) clinics, providing a financial incentive to prescribe drugs with higher markups. As expected, the prescriptions of physicians in VI clinics respond positively to the brand/generic markup differential. Interestingly, however, Iizuka also

\footnotetext{
${ }^{12}$ It may be beneficial in keeping busy physicians informed of new advances in pharmaceutical treatments and details regarding their use. It may be harmful for the obvious reason that marketers may present biased information on the costs and benefits of risky and expensive drugs.

${ }^{13}$ It is important to note that Medicaid PDLs are the strictest kind of formulary, in which non-preferred drugs are not merely offered at higher copays, but not covered at all. 
finds that physicians in VI clinics are more responsive to the brand/generic price difference faced by patients, suggesting that because they sell the drugs themselves, these physicians "may be better informed about the price difference between generic and brand-name drugs," and "the information advantage of VI doctors may make the doctor a better agent for the patient." Similarly, U.S.-based surveys find that despite a widespread reported desire to take patient costs into account, $60-70 \%$ of physicians "never or rarely" know a patient's pharmacy benefit structure or copayments for different drugs [Shrank et al., 2005, Khan et al., 2008].

\subsection{The Pharmacist}

Most individuals in our sample (77\%) fill their first statin prescription at a retail pharmacy, while the others purchase by mail. Surveys reveal that it is usually at the pharmacy that a patient first learns her copay for the drug prescribed [Shrank et al., 2006]. Physicians and pharmacists alike believe it is a pharmacist's duty to review a patient's plan formulary for cost-saving alternatives, before filling a prescription for a non-formulary or high-tier drug. ${ }^{14}$ The pharmacist must contact the physician's office to request approval for any switch, however. ${ }^{15}$ This is referred to as therapeutic interchange: interchanging prescriptions for similar, but not molecularly identical, drugs.

In contrast, generic substitution (supplying a generic version of a prescribed drug molecule) does not require contacting the prescribing physician. In all 50 states, pharmacists are either mandated or allowed to dispense generic versions of a multi-source drug molecule, as long as the prescriber has not explicitly prohibited it. ${ }^{16}$ While low rates of generic substitution were a policy concern a few decades ago, rates have increased dramatically with the state-level mandates, combined with the fact that pharmacies may earn more from dispensing generic prescriptions than from multi-source brands. Also, most plan formularies now require patients to pay the highest levels of cost-sharing for brand versions of multi-source molecules, and sometimes the full retail price difference between the brand and generic versions. Thus, in this study we do not focus on

\footnotetext{
${ }^{14}$ Only 25 percent of physicians believe that it is their responsibility to prescribe preferred drugs, while 68 percent believe it is the pharmacists' responsibility to check a drug's formulary status. The same physicians report that about 20 percent of their prescriptions result in a pharmacist's call about nonformulary status, and that in 53 percent of these cases, they approve prescription changes (Shrank et al. [2006]).

${ }^{15}$ The very few exceptions include prescriptions written by hospital doctors and filled in hospital pharmacies, and other cases in which doctors belonging to a closed network may be contractually obligated to give ex ante approval for pharmacists to interchange prescriptions within certain drug classes.

${ }^{16}$ Multi-source refers to multiple manufacturers producing and selling the same drug molecule; this can only occur when a drug is no longer protected by a patent.
} 
whether prescriptions for a multi-source drug (i.e. one that is available as a brand or a generic) result in a generic fill, but rather, on the prescriber's choice between a multi-source drug and a single-source drug, which is not available as a generic. Importantly, while the higher price spreads of generics could lead pharmacists to suggest therapeutic interchange to patients, contacting physicians for approval is still required.

\subsection{Patent Expiration}

New drugs approved by the Food and Drug Administration are eligible for patent protection, which typically lasts 11-12 years after the drug's launch. The Hatch-Waxman Act (1984) instituted a reward of 180-day generic exclusivity to the manufacturer of the first-approved generic version of any drug, as an incentive for rapid entry following a patent's expiration. As a result, the market price of an off-patent drug molecule usually drops gradually at first, and more precipitously after the first 180 days. Copays, however, are affected immediately, since they are predicated on generic status rather than the actual price of a drug.

As mentioned above, generic substitution is extremely common once a generic version of a drug is available, regardless of whether the physician has written the brand or generic name of a molecule. ${ }^{17}$ As Figure 1 shows, for the two drugs whose patents expire during our sample period, generic versions rapidly overtook the full share of initial prescriptions for their respective molecules.

There is typically some media attention surrounding the patent expiration of a major drug, especially when it is the first to expire in a high-profile drug class. In 2006, Zocor was Merck's highest-grossing drug, and its primary competitor, Lipitor, was the highest selling drug in the United States. Consequently, this patent expiration was anticipated to reshape statin prescribing and the profit structure of these two firms, and "Zocor" was mentioned in 289 headlines in $2006 .{ }^{18}$

Patent expiration may also shape prescribing through the cessation of drug company advertising for the patent-losing drug. Due to their large market, statin manufacturers do a significant amount of promotion, both direct to physicians (detailing, free samples) and direct to consumers (e.g. television advertisements). Promotion has been found to significantly affect both physician and patient preferences for drugs (Gönül et al. [2005], Venkataraman and Stremersch [2007, 09]).

\footnotetext{
${ }^{17}$ With the exception of when a physician writes "Do not substitute."

${ }^{18}$ Author's Lexis-Nexis search for articles with "Zocor" or "simvastatin" in the headline, and "generic" in the body, from six months prior to the patent expiration to six months after. 
Huckfeldt and Knittel [2011] find that total prescriptions actually decrease, by around $20 \%$ on average, after patent expiration. They argue that this is explained by the reduction in a drug's advertising. However, as noted by Aitken et al. [January/February 2009] and Scott Morton and Kyle [2011], the case of Zocor typifies a "special class of exceptions" in which the potential price savings dominate: "the entry of a first generic in a large therapeutic class with close substitutes." [Scott Morton and Kyle, 2011]. ${ }^{19}$

\subsection{The Statin Drug Class}

Statins are the first-line recommended drug treatment for high blood cholesterol. A series of longterm studies has demonstrated their efficacy in preventing cardiac events (e.g. heart attacks) among patients with coronary heart disease, and in preventing the emergence of heart disease itself [Grundy et al., 2004]. Today, they are the class of drugs most frequently dispensed in the United States, with 210.5 million prescription purchases in 2009. ${ }^{20}$ Statins are generally well tolerated. Muscle symptoms including soreness, stiffness, tenderness, and weakness, are estimated to affect 5 to $10 \%$ of statin users, while more serious adverse effects (liver damage and rhabdomyolysis) are exceedingly rare. [Rosenson, 2012, Baker and Rosenson, 2012, Joy and Hegele, 2009].

All statins are available in several strength (dosage) levels. Higher strength levels (measured in milligrams) achieve greater cholesterol reductions, but also pose a higher risk of side effects. For this reason, high doses of less potent statins are prescribed much less often than low doses of more potent statins.

During our sample period, two statins faced patent expiration. Zocor (simvastatin) was the second most prescribed statin at the time of its patent expiration (15.8\% of initial fills in our sample), and it was roughly in the middle of the existing statins in its potency ranking. Pravachol (pravastatin), which also underwent patent expiration in 2006, was much less commonly prescribed (4.5\%), most likely due to its lower potency. At the start of our study period, there was one older statin available as a generic (lovastatin), which was also infrequently prescribed (6.7\% of initial fills in our sample). The two newest statins, Lipitor and Crestor, are both more potent than Zocor.

\footnotetext{
${ }^{19}$ Of course, factors other than physician agency, including "utilization management" strategies employed by insurers, contribute to the response of prescriptions to this type of event. To deal with this concern, we present several supplemental analyses that strengthen our conclusion that the efforts of physicians to reduce the copays of price-sensitive patients form a large part of the story.

${ }^{20}$ Including Zetia (ezetimbe) which is not a statin. Source: IMS National Prescription Audit PLUS
} 
Vytorin is a combination of simvastatin with ezetimbe, another cholesterol-lowering agent. Thus, it is also more potent than simvastatin alone. ${ }^{21}$

The table below shows the smallest dose of each statin that can achieve a cholesterol reduction in the $30-40 \%$ range, and its patent status in 2006 .

Table 1: Doses of Available Statins Required to Attain an Approximate $30 \%$ to $40 \%$ Reduction of LDL-C Levels and Patent Status in 2005

\begin{tabular}{lccc}
\hline Drug & Dose, mg & LDL Reduction & Patent Status (2006) \\
\hline Lescol (fluvastatin) & 80 & $35 \%$ & On-patent \\
Mevacor (lovastatin) & 40 & $31 \%$ & Off-patent since 2001 \\
Pravachol (pravastatin) & 40 & $34 \%$ & Expired on April 20, 2006 \\
Zocor (simvastatin) & 20 & $35 \%$ & Expired on June 23, 2006 \\
Lipitor (atorvastatin) & 10 & $39 \%$ & On-patent \\
Crestor (rosuvastatin) & 5 & $39 \%$ & On-patent \\
\hline
\end{tabular}

Source: Grudy et al. and NCEP (2004)

Recommended guidelines for statin treatment provide detailed instructions for determining a patient's heart attack risk based on several risk factors such as diabetes, high blood pressure, and smoking, and they provide tables with "goal" cholesterol levels for patients in different risk categories. Physicians are directed to first determine the percentage by which a patient's LDL level ought to be reduced, based on the difference between their current LDL level and their goal level, and then to prescribe a drug at a strength level sufficient to achieve this reduction. ${ }^{22} \mathrm{~A}$ succinct version of this table, as published in the pocket manual most commonly used as a prescribing reference by physicians, is shown in the Appendix.

\section{Data}

The data used in this paper come from the full medical and pharmaceutical claims for over 150 distinct employee and retiree plans offered by 29 Fortune 500 firms from 2005-2007, with full-year coverage of 1,440,020 primary beneficiaries and 3.0 million lives in 2006 .

Medicare Part D, which offers pharmaceutical benefit plans to Medicare beneficiaries, came

\footnotetext{
${ }^{21}$ We refer to Vytorin as a different molecule since it is impossible to unbundle the two active ingredients, simvastatin and ezetimbe.

${ }^{22}$ The guidelines also report a lower LDL cutoff at which physicians should recommend "lifestyle changes" such as better eating and exercise.
} 
into effect in 2006, during the period we study. While this reform did not directly affect retirees who already received pharmacy benefits from their employer, it is difficult to rule out indirect effects on retiree plan copays or on prescribing toward the elderly. To avoid these complications, we exclude retirees and elderly employees from our sample, focusing on actively employed workers (and their dependents) between the ages of 30-64. These individuals represent $96 \%$ of all non-retired statin starters in the dataset. Further, we limit our study to the sixteen firms that report beneficiary salaries. These are reported in $\$ 10,000$ bins ranging from Under $\$ 50,000$ to Above 250,000. These employers range in size from 3,639 to 111,145 primary beneficiaries with full-year coverage in $2006 .^{23}$

The drug claims include detailed information on each drug fill, including NDC number (National Drug Code), days supplied, place of fill (mail or retail pharmacy, in/out of network), date, and all amounts paid (copay or coinsurance, amount paid by plan, deductibles and other non-covered amounts paid by patient). Drug fills were matched by NDC numbers to Thompson Redbook data, to obtain additional characteristics such as drug strength, generic status, and therapeutic class.

Through the corresponding medical claims, rich patient medical information is available for the length of each patient's tenure within a plan. We use diagnosed chronic conditions, number of doctor visits and drugs purchased, as well as age, sex, and 3-digit zip code of residence.

Individual prescribers can be tracked through masked identifiers. However, a large number of prescribers appear in the data $(496,882)$ with few prescriptions across all drug classes (median $=6,99$ th percentile $=317)$. In our sample of initial prescriptions, $49 \%$ have unique prescribers, and only $17.5 \%$ come from one of 620 prescribers with $5+$ initial fills. ${ }^{24}$

Lacking information on physician areas of specialty, we calculate each prescriber's share of prescriptions for cardiovascular drugs (the therapeutic group containing statins, antihypertensives, and other drugs frequently prescribed by cardiologists). The distribution is bimodal (see Appendix Figure 12), suggesting 0.6 as a natural breakpoint. We use this cutoff to impute a "cardiac specialist" dummy equal to one if more than $60 \%$ of a physician's observed prescriptions are for cardiovascular drugs.

In our analysis of prescribing, the key independent variable is plan copay. In the analysis of

\footnotetext{
${ }^{23}$ The identities of the firms are not known, and it is possible that some of them offer other plans to their employees that are not included in these data.

${ }^{24}$ In our copay-verified sample (defined in the Section 3.3) only $11 \%$ come from 173 prescribers who have 5 or more observed initial prescriptions.
} 
how copays affect patient adherence, the outcome variable is six-month adherence to any statin. This is defined as having purchased at least $80 \%$ of the necessary quantity of statin to take one pill per day for the first six months, i.e. at least 144 days' worth of pills. We allow patients to switch to a different statin and still be classified as adherent because we aim to measure the costs of suboptimal prescribing on adherence to statin therapy; if switching costs were low, then the initial prescribing decision would matter less.

Previous experiences with prescribed drugs can allow patients to learn about their benefit coverage, and physicians to learn about their patients' adherence tendencies and preferences over drugs. We define two variables to capture the extent of patient drug history and patient-physician

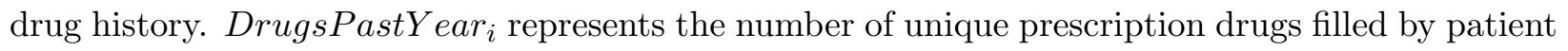
$i$ in the 365 days prior to her initial statin fill. SameDocDrugs $s_{i d}$, which must be less than or equal to DrugsPastYear ${ }_{i}$, counts the unique prescriptions drugs that were prescribed to patient $i$ by doctor $d$, the prescriber of the initial statin fill.

\subsection{Defining our sample of initial statin prescriptions}

We define an initial prescription as a patient's first fill in the statin class after at least one year. Of those who are observed for two years prior to an initial prescription, $17 \%$ had at least one statin fill between 730 and 365 days before the "initial" fill used in the analyis. We control for this occurrence, and for the specific drug previously purchased, in the analysis. ${ }^{25}$

\subsection{Defining the choice set}

The table below shows how the different available dosages of the top six statins in 2005 can be grouped into narrow ranges of expected LDL reduction. As discussed in section 2.5, physicians use a standard calculation of risk factors to determine the level of LDL reduction needed by each patient. Thus, to accurately analyze prescribing, we must consider how the level of desired efficacy eliminates some statins from a prescriber's choice set.

We study the choice of drug among observed prescriptions in the middle three strength categories, which comprise $83 \%$ of initial prescriptions, and assume that these prescribers had the

\footnotetext{
${ }^{25}$ Because many employers were not included in the sample prior to 2005 , our sample size would drop by $41 \%$ if we strengthened the requirement to "first fill after at least two years."
} 
Table 2: Statin dosages available at each range of expected LDL reduction

\begin{tabular}{lrrrrrrr}
\hline & \multicolumn{1}{c}{$(1)$} & \multicolumn{1}{c}{$(2)$} & \multicolumn{1}{c}{$(3)$} & \multicolumn{1}{c}{$(4)$} & \multicolumn{1}{c}{$(5)$} & $(6)$ & \multicolumn{1}{c}{$(7)$} \\
Average LDL reduction & $<26 \%$ & $28-32 \%$ & $34-39 \%$ & $40-47 \%$ & $50-52 \%$ & $57-59 \%$ & $60-70 \%$ \\
\hline lovastatin & $20 \mathrm{mg}$ & $40 \mathrm{mg}$ & $80 \mathrm{mg}^{*}$ & & & & \\
Pravachol & $10 \mathrm{mg}$ & $20 \mathrm{mg}$ & $40 \mathrm{mg}$ & $80 \mathrm{mg}$ & & & \\
Zocor & $5 \mathrm{mg}$ & $10 \mathrm{mg}$ & $20 \mathrm{mg}$ & $40 \mathrm{mg}$ & $80 \mathrm{mg}$ & & \\
Lipitor & & & $10 \mathrm{mg}$ & $20 \mathrm{mg}$ & $40 \mathrm{mg}$ & $80 \mathrm{mg}$ & \\
Vytorin & & & & $10 \mathrm{mg}$ & $20 \mathrm{mg}$ & $40 \mathrm{mg}$ & $80 \mathrm{mg}$ \\
Crestor & & & & $5 \mathrm{mg}$ & $10 \mathrm{mg}$ & $20 \mathrm{mg}$ & $40 \mathrm{mg}$ \\
\hline Share of & .04 & .06 & .36 & .26 & .22 & .06 & .005 \\
Initial Rx & & & & & & & \\
\hline
\end{tabular}

Table constructed using mean percent LDL cholesterol lowering from manufacturers' prescribing information as reported in Smith et al. [2009]

* While $80 \mathrm{mg}$ is the maximum recommended daily dose of lovastatin, it requires taking two $40 \mathrm{mg}$ pills. All other doses shown are commercially available as one pill.

five drugs that appear in these three categories in their choice set. We drop from our sample any observed prescriptions for drug doses expected to reduce LDL by $32 \%$ or less, since it is unlikely the prescribers considered Vytorin and Crestor as alternatives. Similarly, we drop observed prescriptions expected to reduce LDL by $57 \%$ or more, since it is unlikely the prescribers considered Zocor or Pravachol. Notice that the only statin available as a generic in 2005, lovastatin, was not available in a single dose high enough to be considered in the middle three strength categories. This may explain why it was rarely prescribed (4.7\% of initial prescriptions in 2005 ) despite costing substantially less than any other statin. Similarly, another weak statin shown in Table 1 (fluvastatin) is excluded from our study entirely, because received less than $1 \%$ of prescriptions. The patent expiration of Pravachol in April 2006 was the first one that directly affected the choice set in the more common strength ranges, and that of Zocor in June 2006 was the first one to offer generic options spanning the three most common strength ranges.

Our definition of the choice set is bolstered by two findings (shown in the Appendix). First, in our conditional logit regressions, we use a slew of patient characteristics including diabetes, hypertension, past heart attacks, and age group, as controls, yet only one of them (a diagnosis of high cholesterol) has jointly significant effects on the five drugs' choice probabilities. Second, the distribution of drugs prescribed by physicians imputed to be cardiac specialists is very similar to the distribution of drugs prescribed by other physicians. Neither of these findings remains true when 
we consider the entire set of seven statins as one choice set. Given that our use of a multinomial logit model requires the independence of irrelevant alternatives, the choice set we have defined is preferable to using the full set of initial statin prescriptions across the seven columns above.

\subsection{Verified Copay Sample}

While the claims data report exact out-of-pocket payments for each drug fill, these vary by type of fill (e.g. by mail or retail pharmacy, and number of days supplied). For the conditional logit analysis done below, we must know the prices faced by each patient for options that were not chosen, and we must use a standard copay definition that does not depend on the place of fill or size of fill. We define as "standard" the most common type of fill: a 30-day prescription filled at an in-network retail pharmacy. ${ }^{26}$

Using plan identifiers, we empirically identify each plan's standard copay for each statin in each quarter within 2005-2007. We leave the standard copay undefined in plans (or plan-quarters) in which there does not appear to be one dollar value that applied to the standard fill at least $90 \%$ of the time. While these observations are excluded from the Verified Copay Sample used in the conditional logit analysis, we include them in the analysis of copay effects on adherence, to maximize power, and in the graphical representations of prescribing trends, to ensure that our results generalize to the full sample.

\subsection{Prescribing and Copay Trends}

Figure 2 illustrates the variation in copays across plans, as well as the change in the distribution of Zocor copays upon its patent expiration.

Figures 3 and 4 plot the average drug copays and initial prescribing shares of each statin in our full sample from 2005-2007. It appears that the upward trend in Zocor molecule prescribing may have begun in the quarter prior to its generic entry; this is in fact the national trend. Many insurers began reducing their copays for Zocor in an effort to steer prescribing there, in anticipation of its patent expiration. For the same reason, copays for Lipitor, the most commonly prescribed

\footnotetext{
${ }^{26}$ This specification overestimates the long-term copay differences between drugs, in dollars, since some patients will begin filling prescriptions in large quantities, by mail, once they are settled on a long-term drug. Copays can be $30-40 \%$ lower when filled by mail in 90-day quantities. However, in percentage terms, differences between different drugs' copays remain fairly constant within a plan.
} 
statin, began increasing prior to Zocor's patent expiration. ${ }^{27} \mathrm{~A}$ small, but significant, increase in prescribing followed the patent expiration of Pravachol (pravastatin) in April 2006.

\section{Conceptual Framework}

Since we observe only filled prescriptions, the choice of a drug is a joint decision between patient, pharmacist, and physician. We think of this choice as some function of patient copay, patient price-sensitivity and preferences for certain drugs, doctor preferences based on patient's condition, and any private incentives faced by the doctor to prescribe certain drugs.

One can imagine various types of physicians who prescribe with different goals in mind. For example, "health maximizing" physicians may not view it as their role to make cost-benefit calculations, but simply aim to select the treatment with the best expected impact on a patient's health. ${ }^{28}$ They may or may not consider that the expected health benefit of a drug depends on the likelihood that a patient is adherent, and thus, depends indirectly on its cost. By contrast, physicians who are perfect agents for a patient would consider not just the patient's health but also how the costs of treatment would impact her budget for non-health goods. ${ }^{29}$ Adherencemaximizing physicians might consider costs only when they suspect a patient be cost-sensitive in her adherence decision. Yet other physicians might aim to prescribe cost-effective drugs even to cost-insensitive patients, because they act as agents for insurers, or as good stewards of national health care spending. ${ }^{30}$ In fact, all of these reasons to consider costs have been recently discussed in the medical literature in relation to statin treatment. ${ }^{31}$

We do not attempt to distinguish between these physician types, but simply to measure

\footnotetext{
${ }^{27} \mathrm{~A}$ response to an upcoming cost reduction is also consistent with sophisticated prescribing: if doctors understand that switching costs are high and copay gains will begin in the next period, they will maximize patients' utility and adherence by shifting prescribing towards Zocor in anticipation of its patent expiration.

${ }^{28}$ One survey found that "Although $88 \%$ of physicians agreed that it is important that patients' out-of-pocket costs for prescription drugs are managed, only $25 \%$ strongly or somewhat agreed that it is their 'responsibility' to help. Instead, $69 \%$ of physicians believed that it is the responsibility of the pharmacist to be familiar with patients' out-of-pocket costs." [Shrank et al., 2005]

${ }^{29}$ In medical ethics, the idea of trading off health benefits against costs is somewhat controversial. What is much more acceptable is the idea of taking cost into consideration when choosing between two or more "equally safe and efficacious treatments" [Shrank et al., 2005].

${ }^{30}$ In our analysis, we do not consider insurer costs for 2 reasons: First, we do not observe rebates paid by pharmaceutical firms to insurers, which are an important driver of net costs, and second, other studies find that physicians place more importance on patient costs than on plan costs [Lundin, 2000, Shrank et al., 2005]

${ }^{31}$ In 2011, the National Physicians Alliance included the recommendation to "Use only generic statins when initiating lipid-lowering drug therapy" in its "Top 5" list of internal medicine guidelines for primary care physicians [Good Stewardship Working Group, 2011])
} 
the net effects of patients' copays and their copay-sensitivity on the choice of drug prescribed. While the "good stewardship" motive would encourage physicians to prescribe cost-sensitively to all patients, the two patient-centered motivations (maximizing adherence and perfect agency) should be stronger when a doctor is prescribing to a patient who is more cost-sensitive. Thus, we hypothesize an empirical relationship between patient salary (which is a strong predictor of price-sensitivity of adherence), and the cost-responsiveness of the initial prescription decision.

\subsection{Baseline case and necessary assumptions}

Our first objective is to estimate how the prescribing decision responds to cross-plan variation in copays, and to test if this response is stronger for patients with lower salaries. Suppose the physician's utility from prescribing drug $j$ to patient $i$ is $U_{l s}\left(j, X_{i}, p_{i j}\right)$ if patient $i$ has a low salary, and $U_{h s}\left(j, X_{i}, p_{i j}\right)$ if patient $i$ has a high salary.

We will test the null hypotheses that $d U_{l s} / d p=0$ and that $d U_{h s} / d p=d U_{l s} / d p$, assuming that drug $j$ is prescribed to $\operatorname{drug} i$ if $U_{i j} \geq U_{i k} \forall k \in J$. Even though patients with low salaries are substantially more price sensitive in their adherence decisions, it is possible that $\left|d U_{l s} / d p\right|<$ $\left|d U_{h s} / d p\right|$ if it is harder for the physician to observe the copayments of low salary patients, for example, if low salary patients themselves are less familiar with their plan formularies.

In other words, what we will empirically observe as $d U_{l s} / d p$ could be expressed as $\alpha_{l s} \lambda_{l s}$ where $\alpha_{l s}$ is the response to the physician's expectation of the copay of a low salary patient and $0 \leq \lambda_{l s} \leq 1$ is a dampener reflecting the imperfect observation of $p_{i j}$ for these patients. Similarly, $d U_{h s} / d p=\alpha_{h s} \lambda_{h s}$. We hypothesize that $\alpha_{l s}<\alpha_{h s}<0$ and that $0 \leq \lambda_{l s} \leq \lambda_{h s} \leq 1$ (the copays of low salary patients may be less well observed at the time of an initial prescription). We cannot test these hypotheses without a way to separate $\alpha$ from $\lambda$ for each salary group.

To estimate $\alpha_{h s}$ and $\alpha_{l s}$, we use a large and highly publicized shock in copays associated with the entry of a generic substitute for Zocor. We decompose each patient's copayment into $\bar{p}_{j t}$ and $p_{i j t}-\bar{p}_{j t}$, where $\bar{p}_{j t}$ represents the national average copay of brand or generic drugs (depending on the patent status of drug $j$ at time $t$ ) among employer-insured plans (see Appendix Table 13). Thus, $d U_{h s} / d \bar{p}_{j t}$ and $d U_{l s} / d \bar{p}_{j t}$ are primarily identified by the shift in prescribing of Zocor and Pravachol to high and low salary patients, respectively, after these drugs' patent status changed in mid-2006. 
Under the following assumptions, we can estimate $\alpha_{l s}=d U_{l s} / d \bar{p}_{j t}$ and $\alpha_{h s}=d U_{h s} / d \bar{p}_{j t}$, as well as $\alpha_{l s} \lambda_{l s}=d U_{l s} / d p_{i j t}-\bar{p}_{j t}$ and $\alpha_{h s} \lambda_{h s}=d U_{h s} / d p_{i j t}-\bar{p}_{j t}$.

Assumption 1. For both high and low salary patients, the expected therapeutic benefit of a drug does not differ between its brand and generic versions, and thus, does not change upon patent expiration.

Assumption 2. Physicians are fully aware of when Zocor's patent expiration occurred and the corresponding drop in its average copayment among patients in employer-insured health plans.

Assumption 3. No other factors in the prescribing decision change upon a drug's patent expiration.

These three assumptions are necessary to assert that the responses $d U_{l s} / d \bar{p}_{j t}$ and $d U_{h s} / d \bar{p}_{j t}$ identify the parameters of interest, $\alpha_{l s}$ and $\alpha_{h s}$, respectively. In words, under these assumptions, any increase in prescribing of Zocor, after its patent expiration, is purely driven by a desire to reduce copayments for patients. If these assumptions hold, then we can also identify $\lambda_{l s}$ and $\lambda_{h s}$ as the ratios between the two price responses:

$$
\begin{aligned}
\frac{d U_{l s}}{d\left(p_{i j t}-\bar{p}_{j t}\right)} & =\lambda_{l s} \alpha_{l s} \\
& =\lambda_{l s} \frac{d U_{l s}}{d \bar{p}_{j t}} \\
\lambda_{l s} & =\frac{d U_{l s} / d\left(p_{i j t}-\bar{p}_{j t}\right)}{d U_{l s} / d \bar{p}_{j} t}
\end{aligned}
$$

The same approach applies to estimate $\lambda_{h s}$, and the predictions below follow.

1. If there is more emphasis placed on expected copays in prescriptions to lower income patients $\left(\left|\alpha_{l s}\right|>\left|\alpha_{h s}\right|\right)$, then Zocor prescriptions will increase more for low salary patients upon its patent expiration: $\left|\frac{d U_{l s}}{d \bar{p}_{j t}}\right|>\left|\frac{d U_{h s}}{d \bar{p}_{j t}}\right|$

2. If idiosyncratic plan copay variation is imperfectly observed in prescribing to patients of either salary group $s \in l s, h s$, that is, $\lambda_{s}<1$, then $\left|\frac{d U_{s}}{d\left(p_{i j t}-\bar{p}_{j t}\right)}\right|<\left|\frac{d U_{h s}}{d \bar{p}_{j t}}\right|$

3. If $\left|\alpha_{l s}\right|>\left|\alpha_{h s}\right|$ and $0 \leq \lambda_{l s} \leq \lambda_{h s} \leq 1$, then the difference in the response to Zocor's patent expiration, across patients of different salaries, will be larger than the difference in their 
prescribing response to idiosyncratic plan copay variation: $\left|\alpha_{l s}\right|-\left|\alpha_{h s}\right|>\left|\lambda_{l s} \alpha_{l s}\right|-\left|\lambda_{h s} \alpha_{h s}\right|$, which we will test empirically as $\left|\frac{d U_{l s}}{d \bar{p}_{j t}}\right|-\left|\frac{d U_{h s}}{d p_{i j t}}\right|>\left|\frac{d U_{l s}}{d\left(p_{i j t}-\bar{p}_{j t}\right)}\right|-\left|\frac{d U_{h s}}{d\left(p_{i j t}-\bar{p}_{j t}\right)}\right|$

\subsection{Other incentives faced by prescribers}

Suppose a prescriber's utility for prescribing drug $j$ to patient $i$ is increasing in $T_{d j p t}$, the unobserved external incentives (or disincentives) to prescribe $\operatorname{drug} j$ to a patient of plan $p$ in time $t$. This may include the time costs imposed on physicians by plans' "utilization management" strategies to encourage prescribing of certain drugs, or any incentives from pharmaceutical company representatives to prescribe their drugs. Since we estimate $\frac{d U}{d p_{\bar{j} t}}$ from changes in prescribing upon patent expiration, we must consider two possible sources of bias due to the unobservability of $T_{d p j t}$. First, the fact that drug advertising ceases shortly before the expiration of a drug's patent implies that, if physicians are responsive to drug advertising, our estimate of $\frac{d U}{d p_{j t}}$ will be biased towards zero, as argued in Huckfeldt and Knittel [2011]. On the other hand, if some plans imposed policies, after Zocor's patent expiration, to require a generic Zocor prescription prior to covering another statin, then our estimate of $\frac{d U}{d p_{\bar{j} t}}$ will be biased away from zero.

Due to these possible violations of Assumption (3), we are wary of relying solely on the difference between $\frac{d U}{d p_{j t}}$ and $\frac{d U}{\left(p_{i j t}-\bar{p}_{j t}\right)}$ to identify $\lambda$. However, if we replace Assumption (3) with the following assumption, stating that prescriptions for patients of varying salaries are no differently targeted by utilization management strategies and drug advertising, then we can still rely on predictions 1 and 3 to reject the null hypothesis that $\lambda_{l s}=1$.

Assumption 4. Outside of the copay-induced effect, the effect of Zocor's patent expiration on $U_{l s}$ is the same as its effect on $U_{h s}$, that is, the quantity $\frac{d U_{s}}{d T} \Delta T_{\text {djp }}$ does not vary with $s \in l s, h s$.

Furthermore, if we assume that $\lambda_{h s} \leq 1$, and that the net effect of $T_{d j p}$ on $U$ is non-negative, we can derive bounds for both $\lambda_{h s}$ and $\lambda_{l s}$ :

$$
\begin{aligned}
& \frac{d U_{h s} / d\left(p_{i j t}-\bar{p}_{j t}\right)}{d U_{h s} / d \bar{p}_{j} t} \leq \lambda_{h s} \leq 1 \\
& \frac{d U_{l s} / d\left(p_{i j t}-\bar{p}_{j t}\right)}{d U_{l s} / d \bar{p}_{j} t} \leq \lambda_{l s} \leq \frac{d U_{l s} / d\left(p_{i j t}-\bar{p}_{j t}\right)}{\left(d U_{l s} / d \bar{p}_{j} t-d U_{h s} / d \bar{p}_{j} t\right)}
\end{aligned}
$$




\subsubsection{Imperfectly observed patient price sensitivity}

The baseline case described above does not require that physicians are a priori aware of whether a given patient has a low or high salary; it may be simply be the case that patients exert sufficient influence on the prescribing decision to obtain outcomes that reflect their levels of price sensitivity. On the other hand, the prescribing decision might depend on the physician's awareness of the patient's level of price sensitivity: $\alpha_{i d}$ might be a function of $\tilde{a}_{i d}$, physician $d$ 's current estimate of $a_{i}$, patient $i$ 's private level of price sensitivity.

To shed light into the black box of the initial prescription decision, we can consider situations in which we expect physicians to have a greater a priori awareness of a patient's level of pricesensitivity. Suppose a physician starts with a uniform prior for $a$ for all his patients. There are two types of signals he might receive in the course of treating a new patient. First, he will find out which medications the patient is currently taking. Second, he may learn through the course of his own prescribing to a new patient, observing the patient's adherence response in subsequent office visits. If so, then holding constant the number of different drugs patient $i$ has used in the previous year, the number of those drugs that were prescribed by physician $k$ should be positively correlated with the precision of physician $k$ 's estimate of $\alpha_{i}$. In particular, we would expect past prescribing by the same physician to be valuable when patient $i$ has not taken many drugs in the past year, because the information physician $k$ can glean from current medication use is limited.

This approach is inspired by Altonji and Pierret's model of employer learning about employee productivity. ${ }^{32}$ Patient salaries are predictive of price sensitivity, like AFQT scores are predictive of employee productivity. Physicians do not actually observe patients' salaries, like employers do not observe AFQT scores. If past prescribing experiences facilitate physician learning about patient price-sensitivity, then salary should be more strongly negatively correlated with cost-sensitive prescribing among patients who have had previous prescriptions from the same physician. On the other hand, if the salary gradient of prescribing is mostly due to patient requests for certain types of drugs, or to pharmacist intervention, then we would not expect past experience within a patient-physician pair to be important.

\footnotetext{
${ }^{32}$ Altonji and Pierret [2001] use AFQT score as a predictor of employee productivity that is unobserved by employers, and thus, uncorrelated with employees' wages when entering the labor force. Over time, workers' wages begin to demonstrate a stronger correlation with AFQT score, supporting the hypothesis that employers are gradually picking up signals of each employee's true productivity.
} 
We formalize this approach with the assumptions below. SameDocDrugs $s_{i d}$ represents the number of different drugs prescribed in the past year by physician $d$ to patient $i$, DrugsPastY $r_{i}$ represents the total number of different drugs prescribed to patient $i$ in the past year, and $\tilde{a}_{i d}$ is the prescriber's estimate of patient $i$ 's price sensitivity.

Assumption 5. $E\left[\tilde{a}_{i d}\right]=a_{i}$ and $\operatorname{Var}\left[\tilde{a_{i d}}\right]=\sigma_{i d}^{2}$

Assumption 6. $\frac{d \sigma_{i d}^{2}}{d \text { SameDocDrugs } i d}<0$

Assumption 7. $\frac{d \sigma_{i d}^{2}}{d \text { DrugsPastYear }}<0$

Assumption 8. $\frac{d^{2} \sigma_{i d}^{2}}{d \text { SameDocDrugs }_{i d}^{2}}>0, \frac{d^{2} \sigma_{i d}^{2}}{d \text { DrugsPastYear }_{i}^{2}}>0$ and $\frac{d^{2} \sigma_{i d}^{2}}{d \text { DrugsPastYear }_{i} \text { dSameDocDrugs } i d}>0$

Assumption 9. $E\left[a_{i} \mid\right.$ SameDocDrugs $_{i d}$, DrugsPastYear $\left._{i}\right]=E\left[a_{i} \mid\right.$ DrugsPastYear $\left._{i}\right]$

Assumption 6 states that a physician who has prescribed a greater number of drugs to a specific patient will have a more precise estimate of that patient's $a_{i}$ than a physician who has prescribed fewer drugs to that patient. We also assume that estimates of $a_{i}$ are more accurate for patients who have taken more drugs in the past year (Assumption 7). We assume that the value of SameDocDrugs ${ }_{i d}$ and DrugsPastYear $r_{i d}$ in improving the physician's estimate of $a_{i}$ diminishes as SameDocDrugs $s_{i d}$ and DrugsPastYear id increase (Assumption 8).

While DrugsPastYear ${ }_{i}$ is certainly not randomly assigned, and is likely correlated with $a_{i}$ itself in addition to $\sigma_{i d}^{2}$, we make the assumption that conditional on DrugsPastYear ${ }_{i}$, the value of SameDocDrugs $s_{i d}$ is exogenous to $a_{i}$ (Assumption 9). Consider a patient who has only used two different drugs in the past year, prior to her first statin prescription. We assume that whether zero, one, or both of those drugs were prescribed by the physician currently writing her statin prescription is independent of $\alpha_{i}$, but that in latter case $\left(\right.$ SameDocDrugs $\left.s_{i d}=2\right)$, the prescriber has the most accurate estimate of $a_{i}$.

If it is the case that physicians are always aware of patients' levels of price sensitivity, or if it is solely through patient input in the prescribing process that copays affect the choice of drug, then the length of the prescribing history between a given physician and a given patient should not impact the magnitude of $\frac{d U_{l s}}{d \bar{p}_{j t}}$ or $\frac{d U_{h s}}{d \bar{p}_{j t}}$. On the other hand, if physicians drive the choice of drug and only gradually acquire signals of a patient's price sensitivity, then the difference between $\frac{d U_{l s}}{d \bar{p}_{j t}}$ and $\frac{d U_{h s}}{d \bar{p}_{j t}}$ should increase as these signals accumulate. We will explore this question with 
an empirical analysis of how these quantities vary with SameDocDrugs $s_{i d}$ while holding constant DrugsPastYear .

\section{$5 \quad$ Empirical Specification and Results}

This section presents our main empirical results. We start with our analysis of the initial statin prescribing decision. We use a conditional logit framework to estimate how variation in the five drugs' copays affect their probabilities of being chosen. The basic set-up of our equations is:

$$
U_{i j}=T_{j}+\beta p_{i j}+\text { controls }+\epsilon_{i j}
$$

where $i$ indexes patients and $j$ indexes drugs. The key identifying assumption in our analysis is:

Assumption 10. For all pairs of drugs $j$ and $k$ in a class, the distribution of $\epsilon_{i j}-\epsilon_{i k}$ across individuals is independent of $p_{i j}-p_{i k}$.

This assumption would be violated if plans have private information on which drug is a better match for their beneficiaries, and set their copays accordingly. To gauge the validity of this assumption, in Section 5.4 we test whether estimates of patients' price-sensitivity of adherence depend on the type of plan fixed effects included. If prices are indeed correlated with the unobservable benefits of certain drugs to the patients in certain plans, this should translate into a correlation with patient adherence. Finally, in Section 5.5, we combine results from the prescribing and adherence analyses to estimate outcomes under simulated counterfactuals.

\subsection{Prescribing response to plan-specific copays}

First, we examine prescribing in the period prior to Zocor's patent expiration. Table 4 reports results of a conditional logit model in which the choice set includes five drugs: Crestor, Lipitor, Pravachol, Vytorin, and Zocor. ${ }^{33}$

We estimate:

\footnotetext{
${ }^{33}$ As described in Section 3.2, this is the choice set we have defined for the initial prescriptions in our sample. These five drugs were only available as patented brands in this period prior to Zocor's patent expiration.
} 


$$
\begin{aligned}
U_{i d j}= & T_{j}+\beta_{1} p_{i j}+\beta_{2} p_{i j} \text { HighSal }_{i}+X_{i} B_{j}+\gamma \text { LastDocR }_{j d} \\
& +\gamma \text { LastPatR }_{i j}+\text { monthly time trend }_{j}+\epsilon_{i j d}
\end{aligned}
$$

where $i$ indexes patients, $d$ indexes prescribers, and $j$ indexes drugs. The conditional logit model assumes that $\epsilon_{i j d}$ is distributed EV-1, and that the initial drug chosen from the choice set is the one with the largest value of $U_{i d j}$. $T_{j}$ is a fixed effect for each drug molecule, representing a baseline perceived value of drug $j$. The patient characteristics included in $X_{i}$ (diagnosed conditions, age group, and gender) can affect the perceived value of each drug separately, through $B_{j}$. LastDocRx $x_{j d}$ is an indicator for the drug most recently prescribed by doctor $d$ to another patient starting statin therapy, meant to capture habit persistence. LastPatRx $j$ indicates whether statin $j$ was the last statin taken by a patient, among those patients who have taken statins in the past despite having a one-year "clean" window. ${ }^{34}$

The results of interest are the coefficients on $p_{i j}$ (plan-specific copay for $\operatorname{drug} j$ ) and its interaction with High Salary. They show that in the period prior to Zocor's patent expiration, there was a generally small response to copay variation across plans. The largest estimate, -.14, corresponds to an average marginal effect as follows: a $\$ 10$ decrease in Zocor's copay, holding those of other drugs constant, should move Zocor's prescribing share from $18 \%$ to $20 \%$.

Notably, there are no statistically significant differences in the copay response by salary. This runs counter to what we would expect, if physicians could easily observe copays.

The point estimate of LastDocR $x_{j d}$ indicates that habit persistence is as strong as the predicted effect of a $\$ 42-\$ 51$ copay reduction in this period, and LastPatR $x_{j d}$ has an effect more than twice as large as LastDocR $x_{j d}$. These findings underscore how minor an influence copay has on prescribing, when it is difficult for physicians to observe.

Columns (3) and (6) demonstrate that high salary has no statistically significant effect on any particular drug's intercept, and a Wald test confirms that the added terms are jointly insignificant. ${ }^{35}$

\footnotetext{
${ }^{34}$ We observe that about $13 \%$ of the patients in the sample have received a statin previously, and $58 \%$ of them are re-started on the last statin they took (for which LastPatRx $=1$. For all other patients, LastPatRx 0 for all drugs in the choice set.

${ }^{35}$ For Model 3, Prob $>$ chi-squared $=0.4422$. For Model 6, Prob $>$ chi-squared $=0.5634$
} 
Thus, there is no evidence that physicians are more likely to prescribe certain statins to patients with higher incomes, holding other patient characteristics constant. On this basis, we will omit salary-specific intercepts from the specifications in the next sections, but our results do not change substantially if they are included.

\subsection{Prescribing response to Zocor's patent expiration}

To test whether imperfect copay knowledge is to blame for the small effect of $p_{i j}$, we exploit the patent expiration of Zocor, an event causing a large and observable copay change for the Zocor molecule. We decompose copay into its expectation, $\bar{p}_{j t}$, and each patient's copay deviation $\left(p_{i j}-\bar{p}_{j t}\right)$, to compare physicians' responses to idiosyncratic plan variation in copays versus the large-scale copay change induced by patent expiration. We define $\bar{p}_{j t}$ based on whether drug $j$ was available as a generic in period $t$ : If so, $\bar{p}_{j t}$ equals the national average copay of generic drugs for employer-insured patients, and otherwise, it equals the national average copay of brand drugs for employer-insured patients, according to Kaiser Family Foundation's annual surveys of employersponsored health insurance [Kaiser Family Foundation, 2007]. ${ }^{36}$

We estimate:

$$
\begin{aligned}
U_{i d j t}= & T_{j}+\beta_{1} \bar{p}_{j t}+\beta_{2} \bar{p}_{j t} \text {HighSal }_{i}+\beta_{3}\left(p_{i j t}-\bar{p}_{j t}\right)+\beta_{4}\left(p_{i j t}-\bar{p}_{j t}\right) \text { HighSal }_{i} \\
& +X_{i} B_{j}+\gamma_{1} \text { LastDocR }_{j d}+\gamma_{2} \text { LastPatR }_{i j}+\epsilon_{i j}
\end{aligned}
$$

Results are shown in Table 5 . The significance of $\bar{p}_{j t} \mathrm{HighSal}_{i}$ in all models demonstrates that prescriptions are substantially more responsive to expected copays when the patient has a salary below $\$ 50,000$ (the omitted category). In the previous table, by contrast, we saw that low salary patients were no more likely than high salary patients to receive lower cost drugs when only patented drugs were in the choice set. Figure 5 shows that this result extends to the full sample: the increase in prescribing of pravastatin and simvastatin was much larger for low-salary patients.

If $p_{i j t}$ were perfectly observed, and if patent expiration did not change factors of the prescribing decision aside from drug copays, then we would expect $\beta_{1}=\beta_{3}$ and $\beta_{2}=\beta_{4}$. Instead, $\hat{\beta}_{1}$ is

\footnotetext{
${ }^{36}$ Another way to define this variable would be using the average copay within a given quarter for a given drug, among the plans in our sample. Our results remain consistent across these two approaches.
} 
significantly larger than $\hat{\beta}_{3}$, implying $\lambda_{L S}=\frac{\hat{\beta_{3}}}{\hat{\beta}_{1}}$ (reported at the bottom of the table) is significantly less than one. Based on the model in Section $4, \lambda_{L S}$ can be interpreted as a measure of how accurately plan-specific copays are observed by physicians at the time of the initial prescription. The corresponding estimator for $\lambda_{H S}$ is $\frac{\hat{\beta_{3}}+\hat{\beta_{4}}}{\hat{\beta_{1}+\hat{\beta}_{2}}}$, and its estimated values are larger than $\lambda_{L S}$ in every specification, suggesting a smaller discrepancy between the responsiveness of high salary patients' prescriptions to expected copays and actual copays.

A comparison of columns (1) and (2) reveals that including a separate linear time trend for

each drug diminishes the magnitude of $\hat{\beta}_{1}$. The specifications with these trends provide extremely conservative estimates of $\hat{\beta}_{1}$, because the gradual increase in Zocor prescribing after its patent expiration is seen as partly a time trend, rather than a gradual response to its abrupt drop in expected copay in mid-2006 (see Figure 4). In columns (3) and (4), we add plan fixed effects (planspecific intercepts for each drug), in order to ensure that large-scale differences between the plans of low and high salary patients are not driving our results. Comparing columns (1) and (3), and (2) and (4), we see that holding plan constant decreases the magnitude of the differences between low and high salary patients, in terms of both $\hat{\beta p}$ and $\lambda$, but the differences remain statistically and economically significant.

\subsection{Past prescribing experience within physician-patient pair}

A physician's differential prescribing of generic Zocor to low and high income patients could be driven by his own private estimate of a patient's price sensitivity, or it could result from the explicit requests of low-salary (high-salary) patients for low-cost (highly advertised brand) drugs. ${ }^{37}$ Since our data include only purchased prescriptions, we cannot separately observe these parts of the prescription process. However, we can examine how prescribing patterns vary with the length of a physician's patient-specific prescribing history. A simple learning model, described in Section 4.2.1, predicts that as physicians acquire patient-specific experience, their estimate of that patient's price sensitivity will become more precise. Thus, if the results of the previous section are at least partially driven by physicians' perceptions of their patients' price sensitivity, the difference in prescribing to low and high salary patients should increase with SameDocDrugs $s_{i d}$, the number

\footnotetext{
${ }^{37} \mathrm{~A}$ third possibility is that pharmacists are more likely to suggest low-cost alternatives after patients express unwillingness to pay a high copay. However, pharmacists must obtain the prescribing physician's permission to change the prescription before the patient can purchase the drug suggested as an alternative.
} 
of drugs prescribed in the past year by prescriber $d$ to patient $i$, holding constant DrugsPastYr $r_{i}$, the number of drugs prescribed to patient $i$ by any prescriber.

In Table 6, we estimate the following equation, to determine how same-doctor past prescriptions impact the effects of $\bar{p}_{j t}$ and $p_{i j t}-\bar{p}_{j t}$ (which we will abbreviate $p_{\text {diff }}$ ) on the initial statin choice for low and high salary patients.

$$
\begin{aligned}
U_{i j d t}= & T_{j}+\beta_{1} \bar{p}_{j t}+\beta_{1 h s} \text {HighSal }_{i} * \bar{p}_{j t}+\beta_{1 S D} \text { SameDoc }_{i d} * \bar{p}_{j t}+\beta_{1 S D h s} \text { SameDoc }_{i d} \text { HighSal } * \bar{p}_{j t} \\
& +\beta_{2} p_{\text {diff }}+\beta_{2 h s} \text { HighSal }_{i} * p_{\text {diff }}+\beta_{2 S D} \text { SameDoc }_{i d} * p_{\text {diff }}+\beta_{2 S D h s} \text { SameDoc }_{i d} \text { HighSal } * p_{\text {diff }} \\
& +X_{i} B_{j}+\gamma_{1} \text { LastDocR }_{j d}+\gamma_{2} \text { LastPatR }_{j i}+\epsilon_{i j}
\end{aligned}
$$

where SameDocid is a dummy variable indicating an above-median number of prescribed drugs in the past year between patient $i$ and doctor $d$. We run the analysis separately for patients above and below the median value of DrugsPastYear. ${ }^{38}$ We can think of patients with 5 or more previous drugs in the past year as more "experienced" with their plan formulary (and possibly in worse health) than patients with 4 or fewer drugs.

In the models estimated, shown in Table 6, we do not include drug-specific time trends, but the results are robust to their inclusion. Before we focus on the SameDoc interaction terms, we note some interesting differences between patients with more and less recent experience with drug prescriptions. By comparing columns 1 and 3, we see that prescriptions to low-salary patients only respond to $p_{\text {diff }}$ (plan-specific copayments) for patients who have had five or more prescriptions in the past year. Prescriptions to high-salary patients, however, respond similarly to $p_{\text {diff }}$ for patients with fewer and more than five past prescriptions. This is consistent with our suspicions that lowsalary patients have a harder time navigating their plan formularies, and that patient familiarity with copays is one driver of the prescribing response to $p_{\text {diff. }}$

We now turn our attention to the effect of physician-specific prescribing experience. Column 2 reveals that among patients with fewer than 5 recently-prescribed drugs, the salary-difference in the response to $\bar{p}_{j t}$ doubles in size with same-doctor prescribing experience. A low-salary patient starting a statin after Zocor's patent expiration becomes significantly more likely to be prescribed

\footnotetext{
${ }^{38}$ We exclude patients with DrugsPastYear $=0$, since they cannot possible have any doctor-specific experience. However, the results do not change if we include these observations.
} 
a generic if the physician has some prescribing history with her, while a high-salary patient does not. By contrast, column 4 shows that among patients with five or more recently prescribed drugs, doctor-specific experience is irrelevant. Two explanations are possible: experienced patients are more likely to verbally express their preferences (for brand or generic drugs) to the current prescriber, or new physicians can infer a patient's preferences through the list of the drugs she reports having used recently.

We also tested a specification that included similar interaction terms for DrugsPastYr $r_{i}$ with the copay and salary variables, to ensure that the results are not driven by the correlation between SameDocDrugs $s_{i d}$ and DrugsPastY $r_{i}$. The coefficients of interest remained statistically significant and similar in magnitude, while the DrugsPastYr interaction terms were insignificant (results not shown). These results extend to the full sample and are graphically displayed in Figures 6 and 7 .

We now turn to an analysis of the copay sensitivity of patient adherence outcomes, which will serve three purposes: First, we can compare estimates of copay elasticities with different levels of controls, to test whether plans set their copays endogenously. This is one way of testing Assumption 10. Second, after estimating copay sensitivity during the period prior to Zocor's patent expiration, we can compare trends in adherence of new patients to the model's predictions, to verify that patients value the drug similarly in its brand and generic versions (Assumption 1). Third, we can make out-of-sample predictions of each patient's adherence to each statin in the choice set, which will allow us to estimate how adherence rates could improve in simulated scenarios, in Section 5.5.

\subsection{Analysis of Patient Adherence Decision}

We use a common medical definition of class-based full adherence over six months (henceforth simply adherence) - filling enough statin prescriptions to maintain a supply of medication during at least $80 \%$ of the days in the six months following the initial fill. While we attribute the choice of drug initially prescribed to the physician (possibly influenced by the patient or pharmacist), we attribute the decision to adhere to statin treatment to the patient. This is because statins are always prescribed as long-term drugs. ${ }^{39}$

\footnotetext{
${ }^{39} \mathrm{~A}$ patient guide to statins by the Mayo Clinic says "Keep in mind that when you begin to take a statin, you'll most likely be on it for the rest of your life. Side effects are often minor, but if you experience them, you may want to talk to your doctor about decreasing your dose or trying a different statin. Don't stop taking a statin without talking to your doctor first."
} 
We estimate a logit equation for patient adherence using only observations in the period prior to Zocor's patent expiration: ${ }^{40}$

$$
Y_{i j}=d_{j}+a_{1} p_{i j t}+a_{2} p_{i j t} * \text { HighSal }+X_{i} B+\gamma_{s}+\epsilon_{i j}
$$

where $Y_{i j}=1$ if patient $i$ is adherent after starting on drug $j$, and $\epsilon_{i j}$ is a Type $1 \mathrm{EEV}$ error. $p_{i j t}$, patient $i$ 's monthly copay, is measured in $\$ 10$ units. Thus $a_{1}$, expected to be negative, represents the average effect of a $\$ 10$ copay increase on a patient's utility of statin treatment. ${ }^{41}$

$d_{j}$ represent fixed effects for the drug molecule prescribed, $\gamma_{s}$ represents fixed effects for the strength category (range of LDL reduction) of the drug prescribed, and $X_{i}$ is a vector of individual characteristics including age decile, gender, salary category, having 0,1 , or $2+$ different diagnoses that call for cholesterol reduction, and DrugsPastYear. If we observe that the patient used a statin in the previous two years (despite a "clean" previous year), we include a dummy for this, as well as a dummy for the case when the same drug is prescribed as before. Finally, we include a dummy for specialist prescribers (imputed), and if the patient's initial fill is for more than 30 days.

Table 7 reports the results of the equation above, estimated in the period prior to Zocor's patent expiration. Marginal effects for the probability of adherence are shown, for a copay change of $\$ 10$. There is a large change in the point estimates between columns (2) and (3), when we add plan fixed effects. The fact that the coefficient on copay moves towards zero indicates that, on average, plans with higher average copays have patients who are less likely to adhere in general. It could also be the case that patients in plans with higher average copays are more price-sensitive than patients in plans with lower average copays. ${ }^{42}$

The most relevant comparison for our purposes is between Models 3 and 4 . In Model 3, the identification of the copay effect comes from the fact that multi-tier plans have different copays for different brand drugs: for example, two plans may have the same copay structure, with their Tier 2 drugs costing $\$ 15$ and their Tier 3 drugs costing $\$ 25$ per month, but one plan may place

\footnotetext{
${ }^{40}$ We restrict the sample to this period because our results in Section 5.2 show that low-salary patients are more likely to be prescribed Zocor once it is available as a generic. Given this selection on observables, we are concerned that selection on unobservables that are correlated with adherence might occur in the post-entry period.

${ }^{41}$ Recall that we use a class-based measure of adherence. As some patients switch to cheaper drugs, our effect of copay on adherence will be smaller than the effect of copay on utility. Nevertheless, this is the margin that is most relevant for assessing health consequences.

${ }^{42}$ One possible reason, which is beyond the scope of this paper, is that plans with higher overall levels of cost-sharing cause income effects, increasing price-sensitivity to the marginal drug prescribed.
} 
Lipitor on Tier 2 and Crestor on Tier 3, while another plan might do the reverse. In Column (4), instead of fixed effects at the plan level, we include fixed effects by planXmolecule. This absorbs permanent differences in tier placements, and identifies the effect of copay from changes in a plan's copay structure or tier placements over time, during the period prior to Zocor's patent expiration.

If plan managers had private information indicating that their own patients would do better on a certain drug, and chose to offer that drug at a lower (or higher) copay level, then Model 3 would overestimate (underestimate) the effect of copays on adherence relative to Model 4. Similarly, if patients had selected into plans based on their generous coverage of a certain statin, then Model 3 would overestimate the effect of copays on adherence. What we find is that the estimates are quite close in Models 3 and 4, suggesting that tier placements within a plan are uncorrelated with unobserved patient preferences for certain drugs. This is reassuring, given that our approach to estimating the effects of copays on prescribing relies on this assumption.

Based on Model 4, a $\$ 10$ copay increase is estimated to reduce a low salary patient's adherence probability by 4 percentage points (corresponding to a $8.5 \%$ reduction). The adherence of high salary patients, however, appears very inelastic, with a $\$ 10$ copay increase reducing adherence probability by only four-tenths of a percentage point. Since the average copay in this period is $\$ 22.21$, these estimates together imply an average elasticity of $-.08{ }^{43}$

In Panel B, we conduct exclusion tests for additional control variables that are included in the prescribing analysis. For example, in the prescribing analysis we allow physicians to have different baseline probabilities for prescribing each drug to patients with different salary and different diagnoses (either 0,1 , or $2+$ diagnoses related to statin therapy). Thus, in models 5 and 6 , we test whether patients with different salaries and diagnoses have different adherence probabilities to different drugs. The results of a Wald test show that these interactions are not jointly significant. In Models 7 and 8, we test the inclusion of variables introduced in section 5.3, relating to prior patient-prescriber experience. These variables are not significant; this reassures us that the results

\footnotetext{
${ }^{43}$ While this is quite a bit smaller than other elasticity estimates in the literature (from -.2 to -.6), there are several reasons why we expect this to be a lower bound. First, using a class-based measure of adherence means we are allowing patients to switch to other drugs. Second, since we do not observe prescriptions that were never filled, we may be missing the prescriptions to the most price-sensitive patients, who chose not to purchase even one month of the drug they were prescribed. (Interestingly, this same data limitation causes us to overestimate the relationship between copays and prescribing.) By contrast, many of the existing estimates in the literature come from comparing aggregate utilization rates across plans, or when a plan changes its copay structure; these estimates include the potential effect of copays on first fills.
} 
of section 5.3 are not driven by underlying differences between patients who have received more or fewer prescriptions from their current prescriber.

We evaluate Model 4 by matching out-of-sample predictions of monthly mean adherence rates to observed mean adherence rates for the Zocor molecule after patent expiration. Since the model is estimated only using the pre-expiry period, the post-period predicted values are based purely on the pre-period association between patient characteristics, copays, and adherence. Figure 8 shows that the model-based probabilities do a reasonable job predicting the adherence trends of all four groups: low vs. high salary patients starting on Zocor vs. other statins. Figure 8 also tells us that the brand or generic status of a drug's manufacturer does not have any meaningful impact on patient adherence rates. If consumers were less likely to adhere to generic Zocor (simvastatin) than to brand Zocor, then the solid line should overestimate the average adherence rates to Zocor in the post-patent period. By visual inspection, it does not.

To summarize, in this analysis of patient adherence decision we have found:

1. Evidence that salary is negatively correlated with price sensitivity.

2. Support for the assumption that plan copays are not endogenous to unobserved patient preferences.

3. Support for the assumption that patients perceive the therapeutic value of brand and generic Zocor similarly.

We will now present simulations of alternate types of prescribing; to evaluate each simulation's effect on adherence, we will predict patient $i$ 's adherence to drug $k$, using out-of-sample predictions from the regression described above (Model 3).

\subsection{Simulation of Prescribing and Adherence under Counterfactual Scenarios}

Using the estimates from our adherence and prescribing analyses ${ }^{44}$ we simulate prescribing and adherence under three counterfactual scenarios. We report predicted changes in aggregate adherence and copays, relative to status-quo prescribing, for four groups: Low salary patients who had fewer than 5 prescriptions in the previous year, and thus, are less familiar with their plan's pharmacy

\footnotetext{
${ }^{44}$ Model 3 in Table 7, combined with Models 2 and 4 from Table 6
} 
benefits ("unexperienced"), low salary patients with 5 or more prescriptions in the previous year ("experienced"), and high salary patients, divided in the same way.

In Table 8, we compare adherence rates for the status-quo set of prescriptions to the minimum and maximum possible levels of adherence conditional on the drug copays faced by each patient. These bounds are calculated after generating predicted values of $q_{i j}$, patient $i$ 's probability of adhering to drug $j$; these depend on patients' specific copays for each drug, as well as their pricesensitivity and baseline preferences for drugs, based on their observable characteristics.

Status-quo adherence rates are roughly halfway between the minimum and maximum values of predicted adherence given the choice set. However, if each patient was prescribed the drug that maximized $q_{i j}$, adherence would increase further, particularly for the group of low salary patients inexperienced with their formularies: their adherence rate would increase from $48 \%$ to $53 \%{ }^{45}$

Table 9 reports average copays for the status-quo set of prescriptions, the set of prescriptions that would maximize adherence, and the set of copay-minimizing prescriptions. Comparing the last two columns reveals that for low salary patients, the adherence-maximizing drugs are almost always the ones with lowest copays. For high salary patients, in contrast, the adherence-maximizing drugs are significantly more expensive than the lowest copay drugs. ${ }^{46}$

The first scenario we consider is one in which physicians have perfect knowledge of $p_{i j}$. Following the assumptions described in Section 4, we take the weight placed on $\bar{p}_{j t}$ to indicate how prescribers would weight plan-specific copays if they observed them, and simulate the choice of a statin for each patient if the weight placed on $p_{i j}-\bar{p}_{j t}$ were equal to the weight placed on $\bar{p}_{j t}{ }^{47}$ In other words, we simulate prescribing when $\lambda=1$ for both low and high salary patients. Details of the simulation are in the Appendix.

The top panel of Table 10 reports our results. 7-9\% of low salary patients receive a different prescription under this simulation, but only 12-15\% of the possible increase in adherence is achieved. For high salary patients, there is essentially no change in prescribing, and thus, no improvement

\footnotetext{
${ }^{45}$ In the experienced group of high salary patients, adherence would increase from $44 \%$ to $48 \%$. For high salary patients, the potential gain in adherence is much smaller (.01) because copays play almost no role in determining their adherence.

${ }^{46}$ Recall that our adherence model allows for patients with different diagnoses and demographics to have different preferences for drug molecules; thus the cheapest drug is not always the one that maximizes the chance of adherence.

${ }^{47}$ We allow these weights to differ between inexperienced and experienced groups of low and high salary patients, as well as between patients who have longer or shorter histories receiving prescriptions from the current physician, as we found in section 5.3 that this experience leads to greater differentiation between low and high salary patients.
} 
in adherence. This is primarily because for high salary patients, we found a smaller discrepancy in the prescribing response to $\bar{p}_{j t}$ and $p_{i j}\left(\lambda_{H S}=.65\right.$ while $\left.\lambda_{H S}=.27\right)$.

In Scenario 2, we combine perfect knowledge of $p_{i j}$ with better precision in the prescriber's estimate of $a_{i}$, by applying the weights placed on copay by physicians with prior patient-specific experience, to all prescriptions. This is a meaningful change for low salary inexperienced patients, who are otherwise more likely to receive similar prescriptions as high salary (less cost-sensitive) patients. For this group, there is an added adherence improvement relative to Scenario 1, resulting in 14 percent of patients receiving different prescriptions, a 1.1 percentage point increase in adherence, and a $\$ 2.66$ reduction in mean monthly copay (see middle panel of Table 10). However, this is still less than one-quarter of the maximum possible adherence gain for this group. For the other three groups, results are no better than in Scenario 1.

As Scenario 3, we assign all patients the drug with the lowest copay on their formulary. ${ }^{48}$ In practice, this could be achieved if plans imposed strict policies requiring that patients try a lowesttier statin prior to receiving coverage for any other statin. As shown in the bottom panel of Table 10, the predicted changes in adherence for low salary patients are $94 \%$ of the possible increase. A back-of-the-envelope calculation predicts that this adherence increase would prevent 5-6 cardiac events per 10,000 low salary statin prescribees, in the year following their first prescriptions. ${ }^{49}$ For high salary patients, the simulation yields small but positive changes in adherence. Furthermore, high salary as well as low salary patients save an average of $\$ 8-\$ 9$ per monthly prescription.

\section{Robustness}

In this section, we show that our main findings are robust to the inclusion of plan and prescriber fixed effects. We also argue, based on the distribution of generic prescribing shares across the plans in our sample, that it is unlikely these plans imposed restrictive policies to maximize generic prescribing. Lastly, we examine the potential bias in our estimates due to the unobservability of

\footnotetext{
${ }^{48}$ In the period prior to Zocor's patent expiration, there were often several drugs available at the same copay. If the status-quo prescription was one of these, we assumed that it did not change. Otherwise, we chose one of the lowest-copay drugs at random.

${ }^{49}$ We used observed rates of cardiac-related ER visits within the sample, in the calendar year following statin initiation, as baseline (3.13\% among unexperienced low-salary patients and $5.6 \%$ for experienced low-salary). We used .62 as the odds ratio effect of statin treatment, as reported for the below-age-65 subgroup in a meta-analysis of RCTs focused on populations with no prior history of cardiac events [Brugts et al., 2009].
} 
unfilled first prescriptions.

\subsection{Plan and prescriber fixed effects}

The copay-verified subsample that we use in Sections 5.1-5.3 does not contain enough observations per prescriber to support prescriber-specific drug intercepts. Here, we use a simple empirical specification that allows us to include both plan fixed effects and prescriber fixed effects. We focus on the period after Zocor's patent expiration and estimate a linear probability model with the binary outcome being a prescription for an off-patent drug:

$$
\text { OffPatent }_{i d}=\beta_{0}+\beta_{1} \text { HighSal }_{i}+X_{i} B+\text { plan f.e. }+ \text { prescriber f.e. }+\epsilon_{i d}
$$

Our goal is to test whether a high salary makes patients less likely to be prescribed an offpatent drug (Zocor or Pravachol) holding constant the plan and the prescriber. Indeed, we find that high salary patients are 8.1 percentage points less likely to be prescribed off-patent drugs (Table 11, models (1) and (2)). In contrast, we show in models (3) and (4) that no salary differential existed for the probability of being prescribed a Tier 2 ("preferred brand") drug, in the period preceding Zocor's patent expiration. ${ }^{50}$

We also use this specification to examine the robustness of the past prescribing effects from Table 6. We estimate the following model in the period following Zocor's patent expiration:

$$
\begin{array}{r}
\text { OffPatent }_{i d}=\beta_{0} \text { HighSal }_{i}+\beta_{1} \text { SameDocDrugs }_{i d}+\beta_{2} \text { HighSal }_{i} \cdot \text { SameDocDrugs }_{i d} \\
+\beta_{3} \text { DrugsPastYear }_{i}+\beta_{4} \text { Specialist }_{d}+X_{i} \text { B }+ \text { plan f.e. }+\epsilon_{i d}
\end{array}
$$

where the binary variable of interest, SameDocDrugs $s_{i d}$ represents the number of prescriptions (for any type of drug) written by physician $d$ and filled by patient $i$ in the past 365 days. The hypothesis drawn from the simple learning model described in Section 4.2.1 is that the difference in prescribing to low and high salary patients grows larger as the physician gains experience prescribing to his patients $\left(\beta_{1}>0\right.$ and $\left.\beta_{2}<0\right)$. To mitigate bias by unobserved characteristics that make patients more likely to have received prior prescriptions from their doctor, we control for Specialist, number of different drugs taken by patient in the previous year (DrugsPastYear) and number of days

\footnotetext{
${ }^{50}$ To increase the comparability between these two time periods, we restrict the sample to plans with 3 or more tier levels in all four regressions.
} 
patient made outpatient visits in the previous calendar year (DocVisits). ${ }^{51}$ To avoid endogeneity due to unobserved characteristics of physicians, we control for $\overline{\operatorname{SameDoc}}_{d}$, the percent of doctor $d$ 's observed patients with at least one prior prescription from physician $d$.

In Table 12, we report results from variations of Equation 6. As before, we estimate it separately for patients below and above the median value (5) of DrugsPastYear $i$. Regardless of the controls added to the model, the hypothesis that $\beta_{1}=0$ is rejected for the case of inexperienced patients: low salary patients become far more likely to get a generic prescription as their physicians accumulate experience prescribing to them. The estimate of $\beta_{2}$ is always relatively close in magnitude (and opposite in sign) to $\beta_{1}$, suggesting that the generic prescribing rate towards high salary patients does not change much as doctors gain more experience prescribing to them. In fact, there is no evidence that low salary inexperienced patients are any more likely than high salary inexperienced patients to be prescribed a generic drug by a doctor who has not prescribed to them in the past. In the group of patients more experienced with their drug plan, however, a difference of 5.8 percentage points is statistically significant. While we lose significant power when doing this estimation as a conditional logit with physician fixed effects, the overall picture is similar (results not shown). These results support the findings of Table 6. At least part of the salary-differential in generic prescribing appears to be driven by gradual physician learning of patient type.

\subsection{Potential bias from insurers' efforts to promote generic drugs}

We have expressed our estimates of $\lambda_{L S}$ and $\lambda_{H S}$, the ratio of responses to idiosyncratic vs. observed price differences, as lower bounds, because part of the response of prescribing to $\overline{j_{j}}$ might be due to complementary actions taken by plans to increase prescribing rates of newly off-patent Zocor. Here, we explore the distribution of generic prescribing by plan in the post-expiration period. If plans implemented prior authorization or step therapy policies, we would expect them to yield high generic prescribing shares for initial prescriptions. In Figure 9, we show the distribution of generic prescribing shares across plans for those used in our full sample as well as our copay-verified sample. ${ }^{52}$ It is worth noting that all of the plans with generic shares smaller than 20 percent belong

\footnotetext{
${ }^{51}$ Unfortunately, the outpatient visit claims data cannot be matched with physician identifiers, so we cannot identify office interactions between a specific patient and physician.

${ }^{52}$ Since plans might have taken some time to enact these policies, we calculate the shares using prescriptions from the year 2007 only, and we exclude plans with fewer than ten initial prescriptions in this time period.
} 
to the same employer, one with an unusual formulary that violates the norm of offering generic drugs at lower copays than other drugs.

The distributions are centered around 35\%. We might suspect that plans with generic shares greater than $50 \%$ are the most likely to have imposed strong incentives on physicians to prescribe a generic; however, our copay-verified sample does not include any plans with a generic share above $50 \%$. Thus, we are confident that our $\lambda$ estimates are not significantly biased by restrictive plan policies that made it difficult for physicians to prescribe brand drugs after Zocor's patent expiration.

\subsection{Potential bias due to purchase non-adherence}

A limitation of our dataset is that we do not observe written prescriptions that were never filled. Our main analysis implicitly assumes that all patients prescribed a statin by their doctor purchased a first supply of some statin medication. Rates of primary non-adherence, or the failure to fill a first prescription, have been estimated as $34.1 \%$ for initial prescriptions of lipid-lowering drugs [Liberman et al., 2010]. To the extent that purchase non-adherence is correlated with copays and cost-sensitivity, its unobservability will bias our estimates. Specifically, it will lead us to overestimate the responsiveness of initial prescriptions to copays (by disproportionately missing prescriptions for drugs with high copays), and to underestimate the effect of copays on adherence (by missing the worst possible adherence outcome).

A few studies have used electronic prescribing information to identify prescriptions that were sent to pharmacies, but never purchased. To calibrate the likely bias in our estimates, we use the results from the only study of this type, to our knowledge, focused on initial prescriptions for cholesterol-lowering drugs [Liberman et al., 2010]. As expected, this study finds that higher copays are associated with higher rates of purchase non-adherence: rates range from $26.4 \%$ when the copay is less than $\$ 10$ to $44.2 \%$ when the copay is greater than $\$ 25$. However, the study does not find significant variation with income level.

In this section, we assume that patients in our sample purchase their first prescriptions at the rates found by Liberman et al. [2010], according to the copay of the drug prescribed. We expand the sample of patients observed from each plan in each quarter in accordance with the chance that each plan's patients do not fill their first prescriptions, based on plan copayments. First, we generate simulated prescriptions for each patient, drawn in a way that does not depend 
on copay (i.e. $\left.\alpha_{L S}=\alpha_{H S}=0\right) .{ }^{53}$ Next, we use the aforementioned probabilities of purchasing the first prescription to draw a hypothetical sample of "observed" patients. Finally, we use a basic conditional logit model (as in Section 5.1) to estimate the "phantom effect" of copay on prescriptions among those that are "observed" (the estimate that is biased by purchase non-adherence). Our goal is to measure how this estimate differs from zero, which was the true effect of copay in the data generation process of the simulated dataset.

In 5000 simulations, we obtain the distribution of copay coefficients shown in Figure 10. It has a mean value of -.115 , which is $55 \%$ of our estimated copay effect using the same approach with our actual data from the full period 2005-2007, and $86 \%$ of the estimate we obtain in period prior to Zocor's patent expiry. These results suggest that a large share of the estimated effect of copays on prescribing could be explained by the endogeneity of first fills. In fact, it is possible that the copay effects reported in Table 4 are entirely explained by endogenous first fills. By contrast, the overall copay response estimated in the full period (Estimate \#2 in Fig. 10), which includes the increase in the Zocor molecule's use following its patent expiration, is too large to be explained by endogenous first fills.

\section{Conclusion}

Drugs that prevent and manage chronic illnesses are hugely cost-effective when used regularly as prescribed, but only 30-50\% of starting patients achieve adequate levels of adherence. ${ }^{54}$ Many previous studies have shown that copays affect adherence rates, and others have expressed concern for the fact that physicians in the U.S. rarely observe the prices faced by their patients. Our study is the first to attempt to estimate the effect of this information problem on drug prescribing and adherence rates, in the context of statin drugs.

We exploit a highly publicized patent expiration as a price shock that most physicians were aware of. We find that the prescribing response to this patent expiration was two to three times as large as the average response to similar-sized idiosyncratic variation in plan copays. This paper makes three additional contributions to our understanding of agency and information problems in

\footnotetext{
${ }^{53}$ The simulated prescription is chosen on the basis of monthly trends in the prescribing of each statin, and randomly generated EEV-1 errors.

${ }^{54}$ Simpson [2006]
} 
drug prescribing. We shed light on how the difficulty of observing copays, and the weight placed by prescribers on copays, both vary with patient income, an important correlate of patient pricesensitivity. Second, we provide suggestive evidence that physicians learn about patient income (or cost-sensitivity) through their own past experiences prescribing to a given patient.

Third, simulations allow us to predict how prescribing would change if physicians could observe cross-plan variations in copays as easily as they can guess the average difference between brand and generic drugs' copays. Unfortunately, the results do not make us optimistic: less than $10 \%$ of low salary patients would receive different prescriptions, reducing the average patient's copay by approximately $\$ 1.50$ and adherence by less than one percentage point. By contrast, if all patients were prescribed the lowest cost drug in their choice set, average copays would fall by approximately $\$ 9$, or $40 \%$, and the adherence rate of low salary patients would increase from $46 \%$ to $50 \%$, shrinking the gap in adherence of low and high salary patients by more than one-third. If physicians were perfect agents for low income patients, they would place much more weight on their copays; the difficulty of observing copays plays only a small role in the larger agency problem.

There are several policy implications of these findings. We cannot conclude that mechanisms making copays easier to observe, such as providing physicians with mobile devices linked to plan formularies, would significantly improve prescribing from the standpoint of maximizing adherence or reducing expenses. We find that the more heavy-handed policy of requiring patients to start with low-tier drugs would benefit low salary patients without harming high salary patients, but we caution that this conclusion is limited to statins, a relatively homogenous drug class.

In future work, we will more broadly examine the welfare effects of patent expirations, given that the presence of a generic allows physicians to sort patients by their price sensitivity. We will also seek to better understand how physicians learn about the preferences of their patients, and what policies could expedite this process to facilitate the matching of patients to drugs. 


\section{References}

Murray Aitken, Ernst R. Berndt, and David M. Cutler. Prescription drug spending trends in the united states: Looking beyond the turning point. Health Affairs, 28(1):w151-w160, January/February 2009. doi: 10.1377/hlthaff.28.1.w151. URL http://content.healthaffairs . org/content/28/1/w151. abstract.

Joseph G. Altonji and Charles R. Pierret. Employer learning and statistical discrimination. The Quarterly Journal of Economics, 116(1):pp. 313-350, 2001. ISSN 00335533. URL http://www . jstor.org/stable/2696451.

Steven K. Baker and Robert S. Rosenson. Muscle injury associated with lipid lowering drugs. In D.S. Basow, editor, UpToDate. 2012.

J J Brugts, T Yetgin, S E Hoeks, A M Gotto, J Shepherd, R G J Westendorp, A J M de Craen, R H Knopp, H Nakamura, P Ridker, R van Domburg, and J W Deckers. The benefits of statins in people without established cardiovascular disease but with cardiovascular risk factors: metaanalysis of randomised controlled trials. BMJ, 338, 6 2009. doi: 10.1136/bmj.b2376.

Randall D. Cebul, James Rebitzer, Lowell J. Taylor, and Mark Votruba. Unhealthy insurance markets: Search frictions and the cost and quality of health insurance. American Economic Review, 101(5):1842-1871, 2011.

Amitabh Chandra, Jonathan Gruber, and Robin McKnight. Patient cost-sharing and hospitalization offsets in the elderly. American Economic Review, 100(1), 2010.

Amitabh Chandra, Jonathan Gruber, and Robin McKnight. The impact of patient cost-sharing on the poor: Evidence from massachusetts. Working Paper 18023, National Bureau of Economic Research, April 2012. URL http://www.nber.org/papers/w18023.

Michael Dickstein. Physician vs. patient incentives in prescription drug choice. Manuscript, 2012.

Hanming Fang and Alessandro Gavazza. Dynamic inefficiencies in an employment-based healthinsurance system: Theory and evidence. American Economic Review, 101(1):30473077, 2011.

Richard G. Frank and Richard J. Zeckhauser. Custom-made versus ready-to-wear treatments: Behavioral propensities in physicians choices. Journal of Health Economics, 26, 2007.

Martin Gaynor, Jian Li, and William B. Vogt. Substitution, spending offsets, and prescription drug benefit design. Forum for Health Economics \& Policy, 10(2):4, 2007. URL http://ideas . repec.org/a/bpj/fhecpo/v10y2007i2n4.html.

Dana P. Goldman, Geoffrey F. Joyce, Jose J. Escarce, Jennifer E. Pace, Matthew D. Solomon, Marianne Laouri, Pamela B. Landsman, and Steven M. Teutsch. Pharmacy Benefits and the Use of Drugs by the Chronically Ill. JAMA, 291(19):2344-2350, 2004.

Dana P. Goldman, Geoffrey F. Joyce, and Yuhui Zheng. Prescription Drug Cost Sharing: Associations With Medication and Medical Utilization and Spending and Health. JAMA, 298(1):61-69, 2007. doi: 10.1001/jama.298.1.61.

Füsun F. Gönül, Franklin Carter, Elina Petrova, and Kannan Srinivasa. Physicians' prescribing responses to a restricted formulary: the impact of medicaid preferred drug lists in illinois and louisiana. American Journal of Managed Care ${ }_{38}{ }^{2005 .}$ 
Jorge Gonzalez, Catarina Sismeiro, Shantanu Dutta, and Philip Stern. Can branded drugs benefit from generic entry? the role of detailing and price in switching to non-bioequivalent molecules. International Journal of Research in Marketing, 25(4):247 - 260, 2008.

Good Stewardship Working Group. The top 5 lists in primary care: Meeting the responsibility of professionalism. Archives of Internal Medicine, 171(15):1385-1390, 2011. doi: 10.1001/ archinternmed.2011.231. URL +http://dx.doi.org/10.1001/archinternmed.2011.231.

Scott Grundy, James Cleeman, C. Noel Bairey Merz, H. Bryan Jr. Brewer, Luther Clark, Donald Hunninghake, Richard C. Pasternak, Sidney C. Jr Smith, and Neil Stone. Implications of recent clinical trials for the national cholesterol education program adult treatment panel iii guidelines. Circulation, 2004. For the Coordinating Committee of the National Cholesterol Education Program, Endorsed by the National Heart, Lung, and Blood Institute, American College of Cardiology Foundation, and American Heart Association.

Elizabeth Hargrave, Jack Hoadley, Laura Summer, and Katie Merrell. Medicare part d formularies, 2006-2010: A chartbook. Technical report, MedPac, October 2010. URL http://www.medpac . gov/documents/Oct10_PartDFormulariesChartBook_CONTRACTOR_RS.pdf.

Judith K. Hellerstein. The importance of the physician in the generic versus trade-name prescription decision. RAND Journal of Economics, 29(1):108-136, Spring 1998. URL http://ideas.repec . org/a/rje/randje/v29y1998ispringp108-136.html.

Bradley Herring. Supoptimal provision of preventive healthcare due to expected enrollee turnover among private insurers. Health Economics, 19:438-448, 2010.

JH Hibbard and PJ Cunningham. How engaged are consumers in their health and health care, and why does it matter. Technical Report 8, Center for Studying Health System Change, 2008. URL http://www. hschange. com/CONTENT/1019/.

Peter J. Huckfeldt and Christopher R. Knittel. Pharmaceutical use following generic entry: Paying less and buying less. Working Paper 17046, National Bureau of Economic Research, May 2011. URL http://www. nber.org/papers/w17046.

Toshiaki Iizuka. Experts' agency problems: evidence from the prescription drug market in Japan. The RAND Journal of Economics, 38(3), 2007.

Toshiaki Iizuka. Physician agency and adoption of generic pharmaceuticals. American Economic Review, 102(6):2826-2858, 2012.

Tisha R. Joy and Robert A. Hegele. Narrative review: Statin-related myopathy. Annals of Internal Medicine, 150(12):858-868, 2009. doi: 10.7326/0003-4819-150-12-200906160-00009. URL +http: //dx.doi.org/10.7326/0003-4819-150-12-200906160-00009.

Geoffrey F. Joyce, Mariana P. Carrera, Dana P. Goldman, and Neeraj Sood. Physician prescribing behavior and its impact on patient-level outcomes. American Journal of Managed Care, 17:e462-e471, 2011. URL http://www.ajmc.com/articles/ Physician-Prescribing-Behavior-and-Its-Impact-on-Patient-Level-Outcomes.

Kaiser Family Foundation. Employer health benefits: 2007 summary of findings. Technical report, The Kaiser Family Foundation and Health Research \& Educational Trust, October 2007. 
Kaiser Family Foundation. Employer health benefits: 2010 summary of findings. Technical report, The Kaiser Family Foundation and Health Research \& Educational Trust, October 2010.

S Khan, R Sylvester, D Scott, and B. Pitts. Physicians' opinions about responsibility for patient out-of-pocket costs and formulary prescribing in two midwestern states. Journal of Managed Care Pharmacy, 14(8):780-789, 2008.

Joshua N. Liberman, David S. Hutchins, Richard G. Popiel, Mihir H. Patel, Saira A. Jan, and Jan E. Berger. Determinants of primary nonadherence in asthma-controller and dyslipidemia pharmacotherapy. The American Journal of Pharmacy Benefits, 2(2), 2010.

Frank Limbrock. Pecuniary and non-pecuniary incentives in prescription pharmaceuticals: The case of statins. The B.E. Journal of Economic Analysis \& Policy, 11(2), 2011.

Douglas Lundin. Moral hazard in physician prescription behavior. Journal of Health Economics, $19(5), 2000$.

NEHI. Thinking outside the pillbox: A system-wide approach to improving patient medication adherence for chronic disease. Technical report, New England Healthcare Institute, 2009. URL http://www.nehi.net/publications/44/thinking_outside_the_pillbox_a_systemwide_ approach_to_improving_patient_medication_adherence_for_chronic_disease.

Robert S. Rosenson. Statins: Actions, side effects, and administration. In D.S. Basow, editor, Up ToDate. 2012.

Fiona Scott Morton and Margaret Kyle. Markets for pharmaceutical products. In M.V. Pauly, T.G. McGuire, and P.P. Barros, editors, Handbook of Health Economics, number v. 2 in Handbook of Health Economics. Elsevier Science, 2011. ISBN 9780444535931. URL http://books.google. com/books?id=Pia95cLN84cC.

William Shrank, Henry Young, Susan Ettner, Peter Glassman, Stephen Asch, and Richard Kravitz. Do the incentives in 3-tier pharmaceutical benefit plans operate as intended? results from a physician leadership survey. American Journal of Managed Care, 11:16-22, 2005.

William Shrank, Sarah Fox, Adele Kirk, Susan Ettner, Clairessa Cantrell, Peter Glassman, and Stephen Asch. The effect of pharmacy benefit design on patient-physician communication about costs. Journal of General Internal Medicine, 21(4):334-339, 2006.

Ross J. Jr Simpson. Challenges for Improving Medication Adherence. JAMA, 2006.

ME Beth Smith, Nancy J Lee, Elizabeth Haney, and Susan Carson. Drug class review: Hmg-coa reductase inhibitors (statins) and fixed-dose combination products containing a statin: Final report update 5. Technical report, Oregon Health \& Science University, 2009. URL http: //www.ohsu.edu/drugeffectiveness/reports/final.cfm.

Robyn Tamblyn, Rejean Laprise, James A. Hanley, Michael Abrahamowicz, Susan Scott, Nancy Mayo, Jerry Hurley, Roland Grad, Eric Latimer, Robert Perreault, Peter McLeod, Allen Huang, Pierre Larochelle, and Louise Mallet. Adverse Events Associated With Prescription Drug CostSharing Among Poor and Elderly Persons. JAMA, 285(4):421-429, 2001. doi: 10.1001/jama.285. 4.421 . 
Anna A. Levine Taub, Anton Kolotilin, Robert S. Gibbons, and Ernst R. Berndt. The diversity of concentrated prescribing behavior: An application to antipsychotics. Working Paper 16823, National Bureau of Economic Research, February 2011. URL http://www.nber.org/papers/ w16823.

Sriram Venkataraman and Stefan Stremersch. The debate on influencing doctors' decisions: Are drug characteristics the missing link? ERIM Report Series Reference No. ERS-2007-056-MKT., 2007, 09 .

S Virabhak and JA Shinogle. Physicians' prescribing responses to a restricted formulary: the impact of medicaid preferred drug lists in illinois and louisiana. American Journal of Managed Care, 2005. 


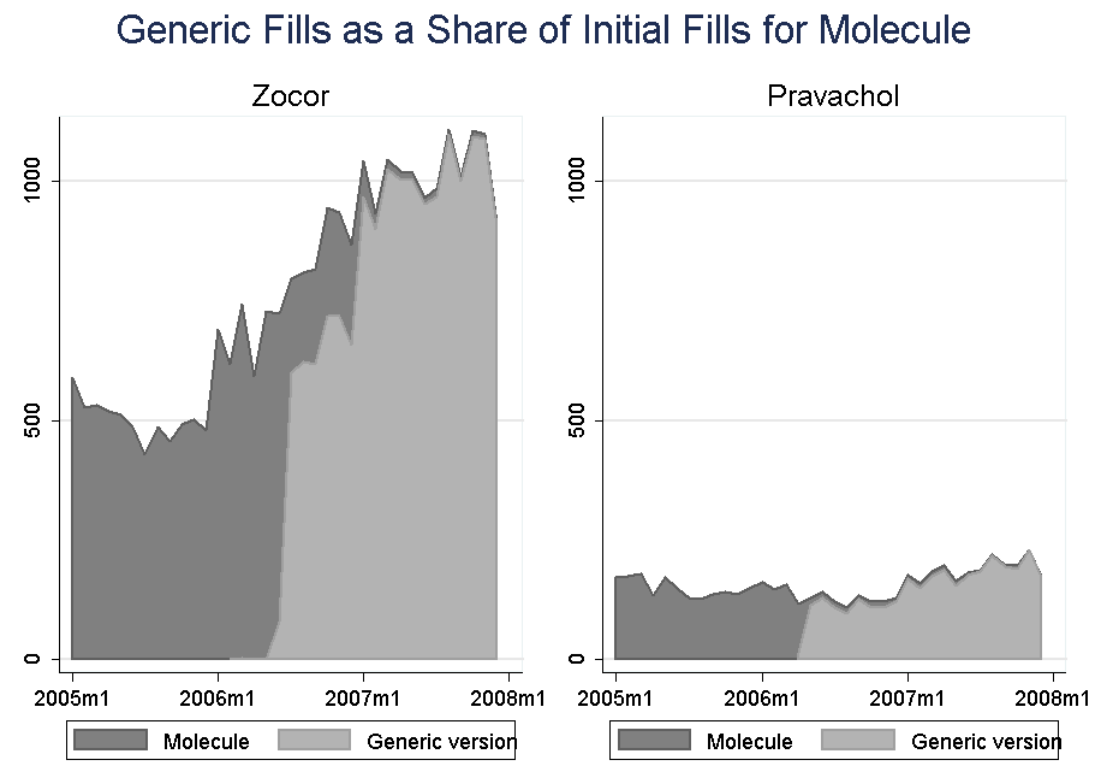

Figure 1: Generic substitution rates, initial prescriptions. The dark gray represents all fills of initial prescriptions for each molecule. The light gray shows the share of fills for generic versions in each period.

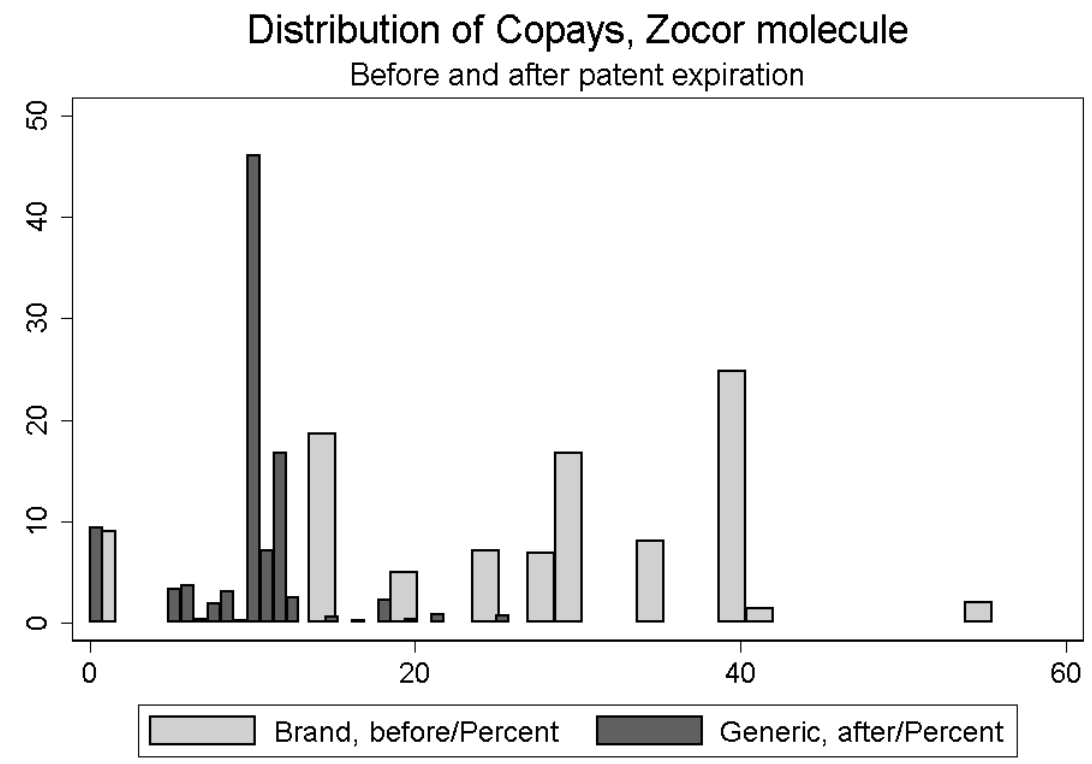

Figure 2: Copay Distribution of Plans in Sample. 


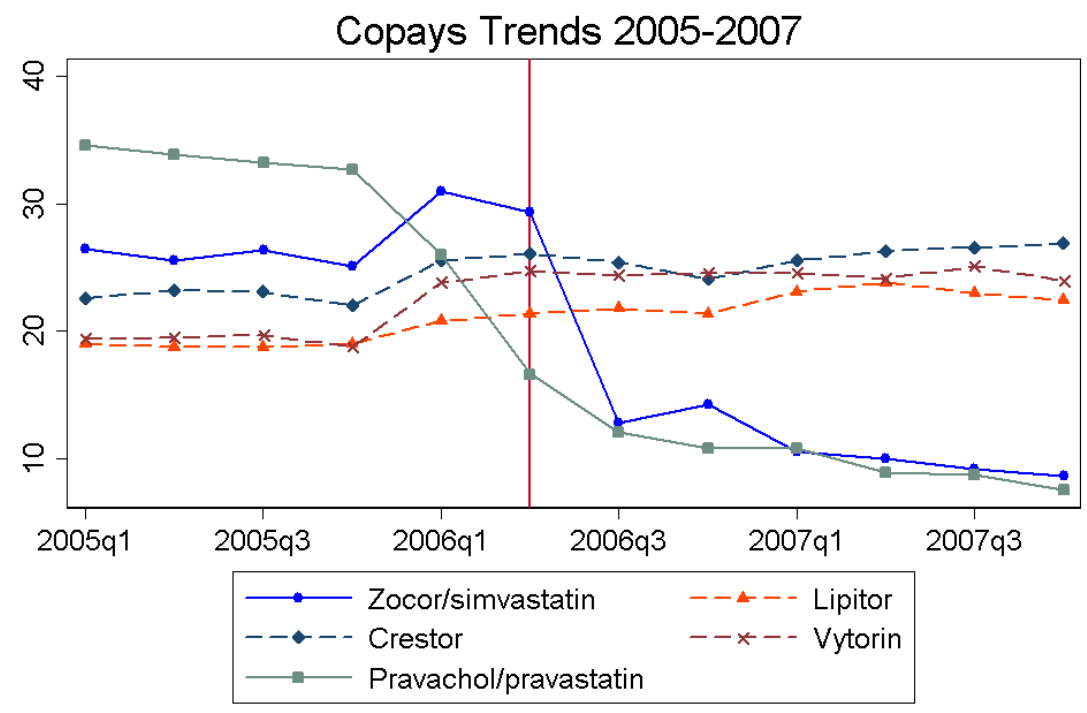

The vertical line marks the quarter in which generic versions of Zocor/simvastatin became available. Generic versions of Pravachol/pravastatin became available in April 2006.

Figure 3: Average copays by molecule, 2005-200\%.

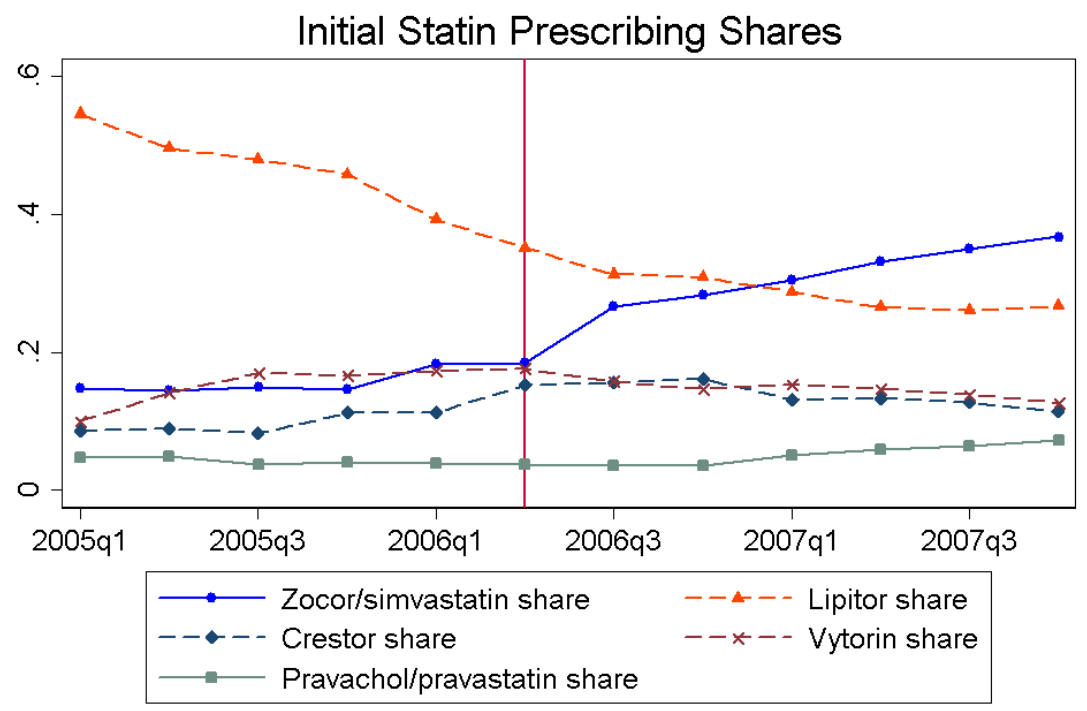

The vertical line marks the quarter in which generic versions of Zocor/simvastatin became available. Generic versions of Pravachol/pravastatin became available in April 2006.

Figure 4: Initial prescriptions. Full sample, 2005-2007. 
Share of initial prescriptions for simvastatin or pravastatin

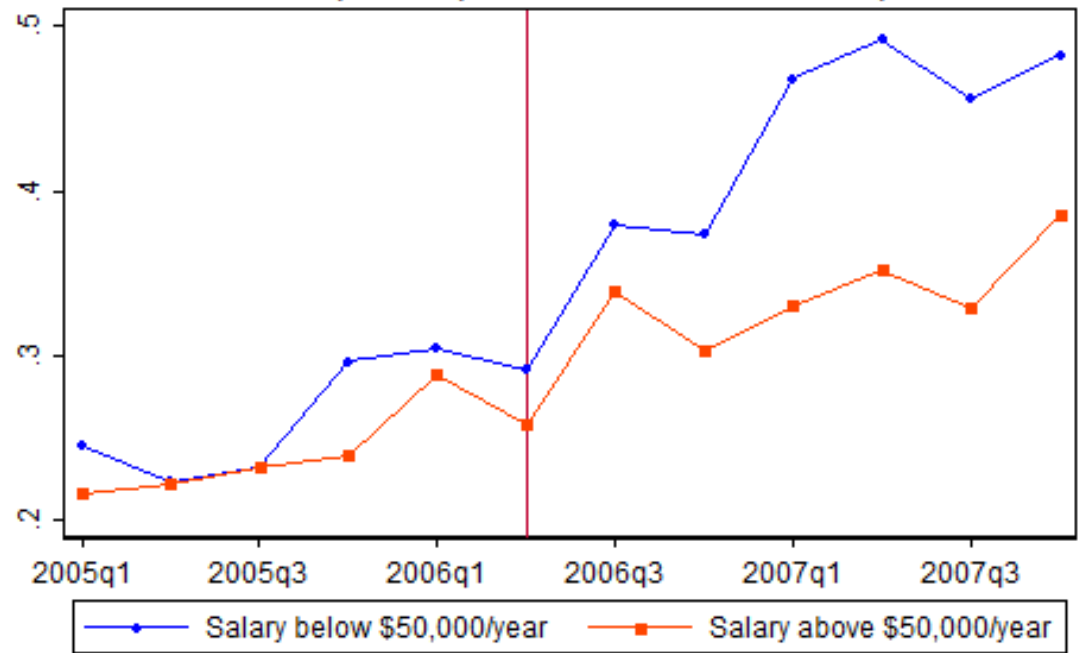

The vertical line marks the quarter in which generic versions of Zocor/simvastatin and Pravachol/pravastatin became available.

Figure 5: Responses to patent expiration by salary, in full sample. 


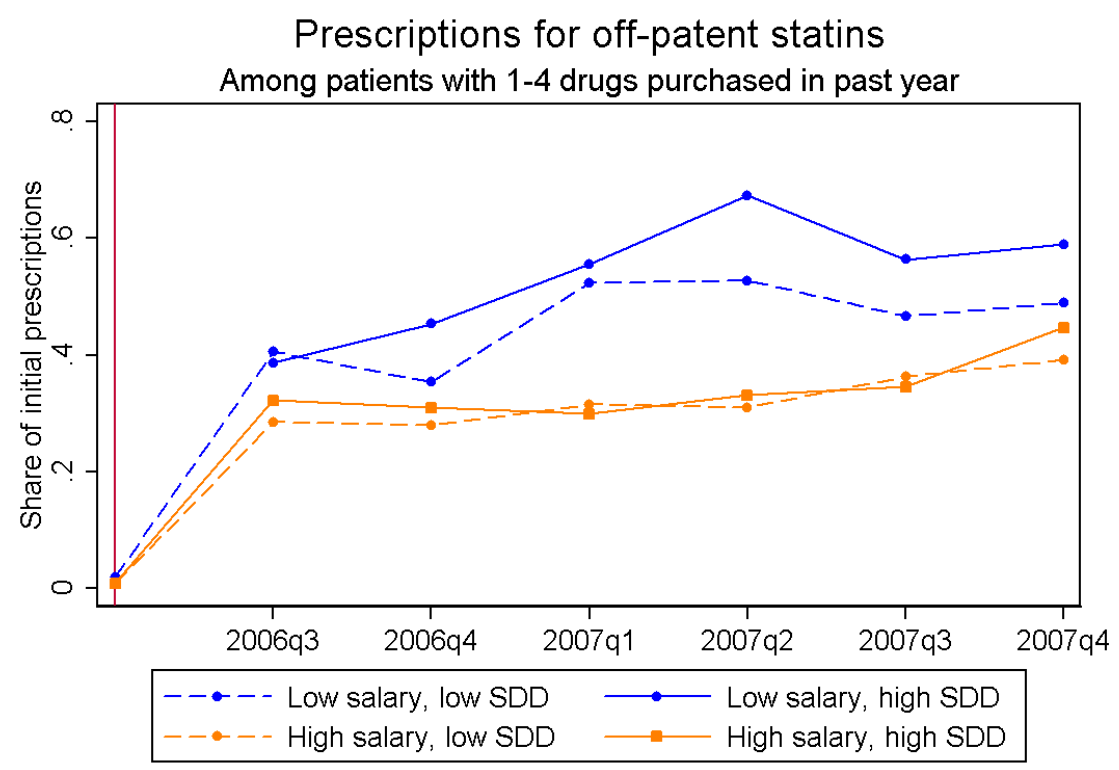

Figure 6: Off-patent prescribing by salary and SDD (SameDocDrugs) SameDocDrugs $s_{i k}$ is the number of different drugs that patient $i$ was prescribed by physician $k$ in the one-year period prior to the initial statin fill, which is also prescribed by physician $k$. "High SDD" is defined as SameDocDrugs $>1$ and applies to $40 \%$ of the low salary group and $35 \%$ of the high salary group. "High salary" is defined as greater than $\$ 50,000$.

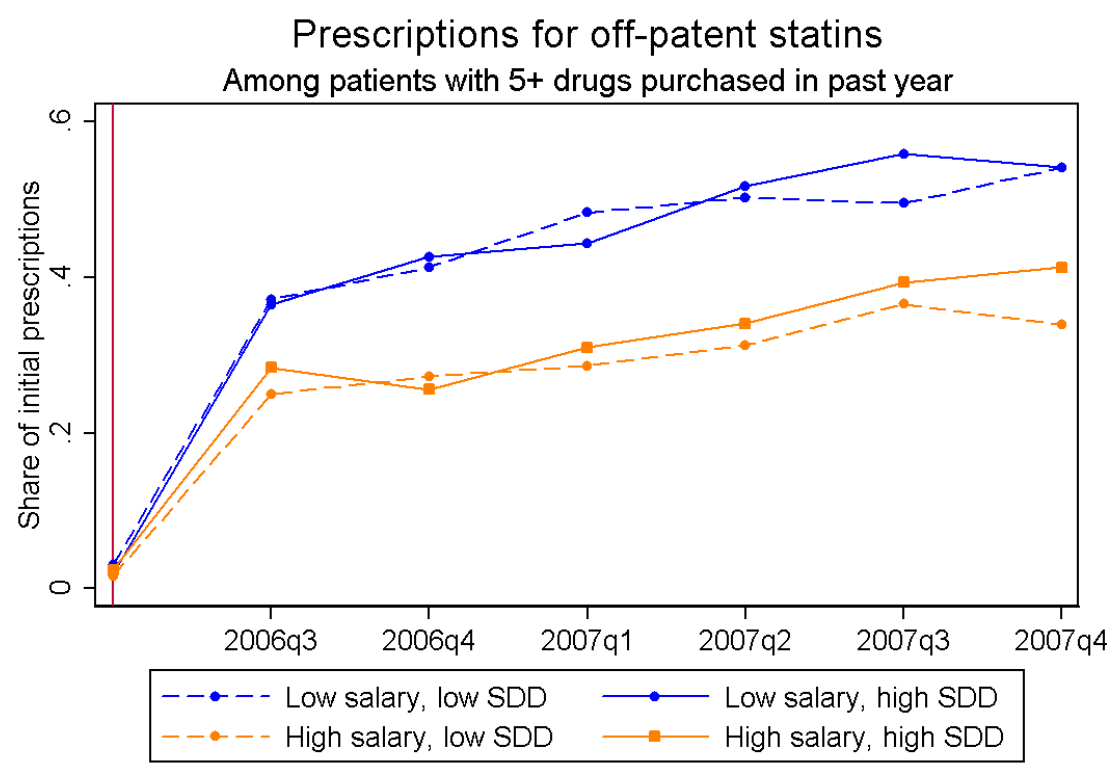

Figure 7: Off-patent prescribing by salary and SDD (SameDocDrugs) This figure corresponds to the one above, but represents a set of patients who use many more prescription drugs overall. Here, "High SDD" is defined as SameDocDrugs > 4 and applies to $43 \%$ of the low salary group and $37 \%$ of the high salary group. 

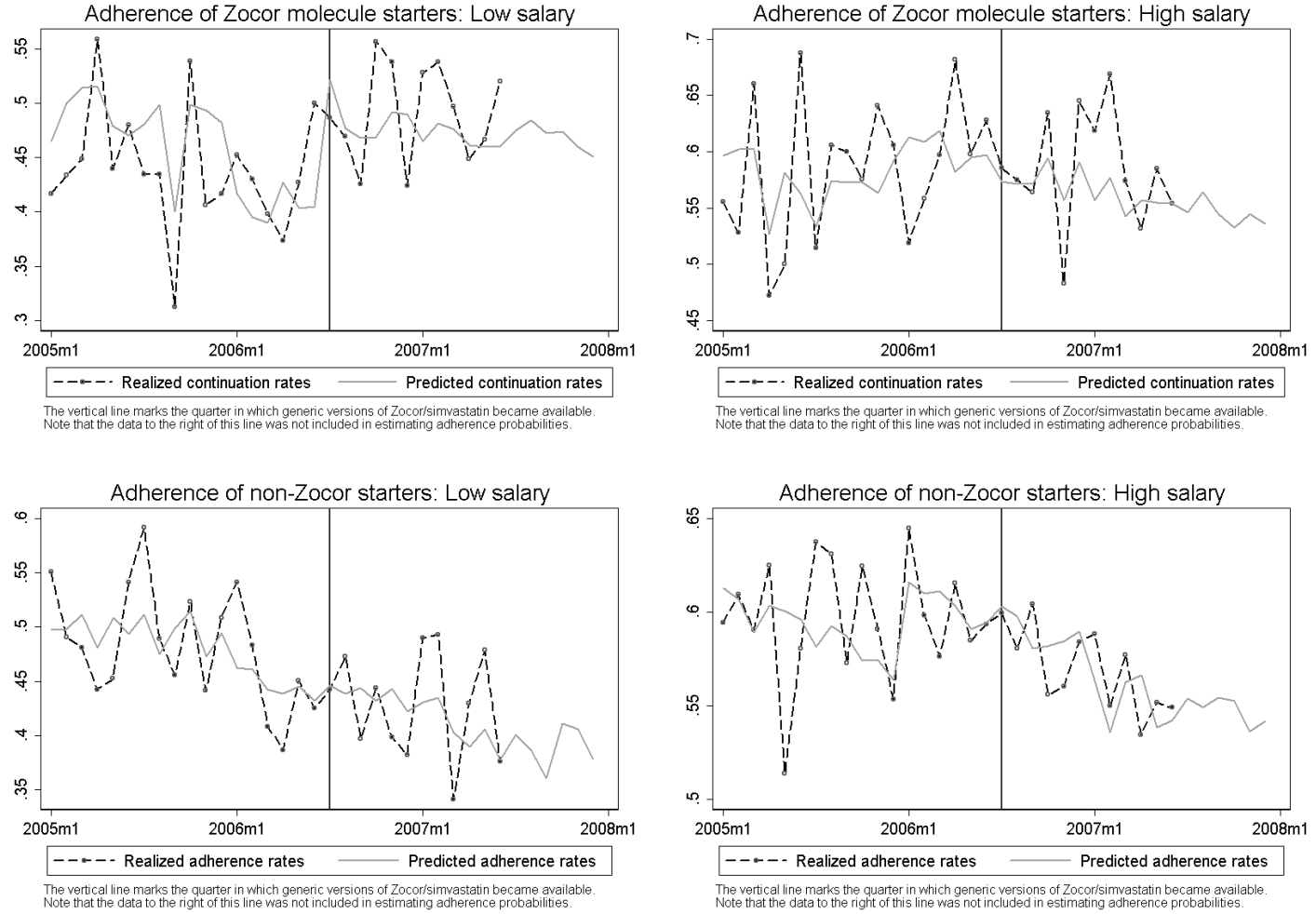

Figure 8: Predicted and Actual Zocor Continuation Rates, by salary groups. These figures compare the predicted values of the model estimated in Table 7 to the actual observed continuation rates of patients initiating statin treatment with a Zocor prescription. 


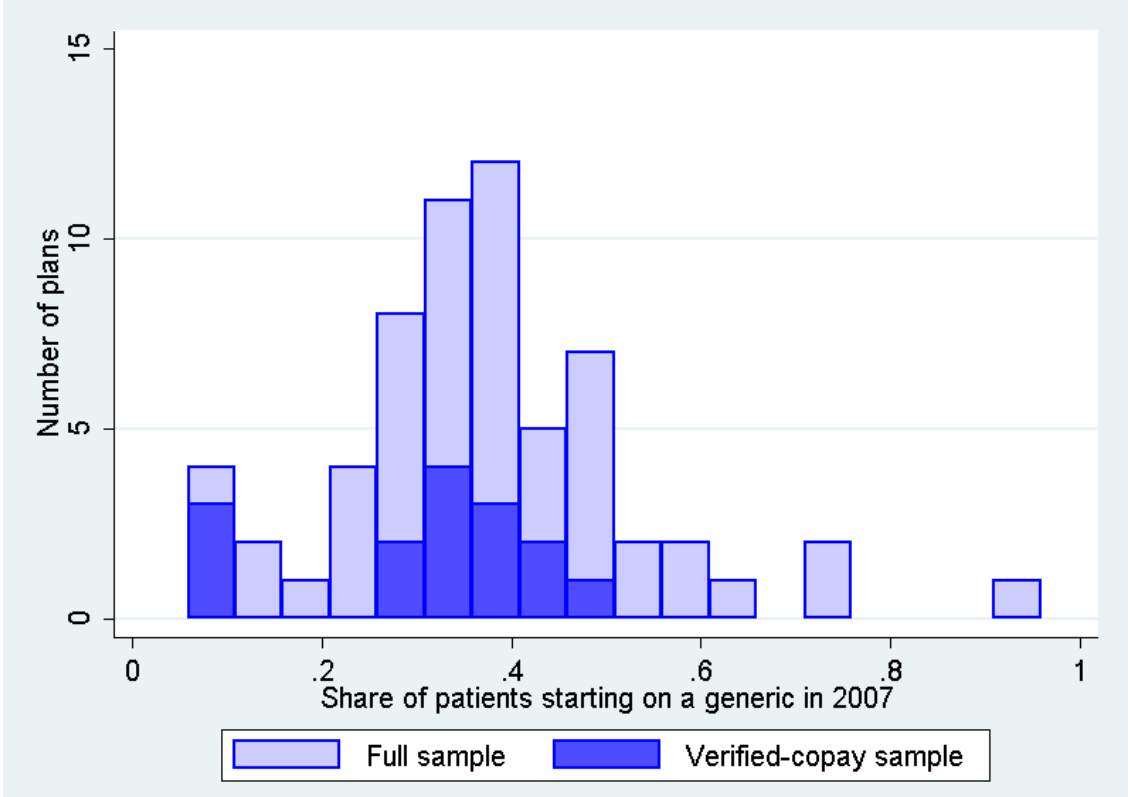

Figure 9: Distribution of Generic Prescribing Shares by Plan, 200\%. Plans with at least ten initial statin prescriptions in 2007 are shown.

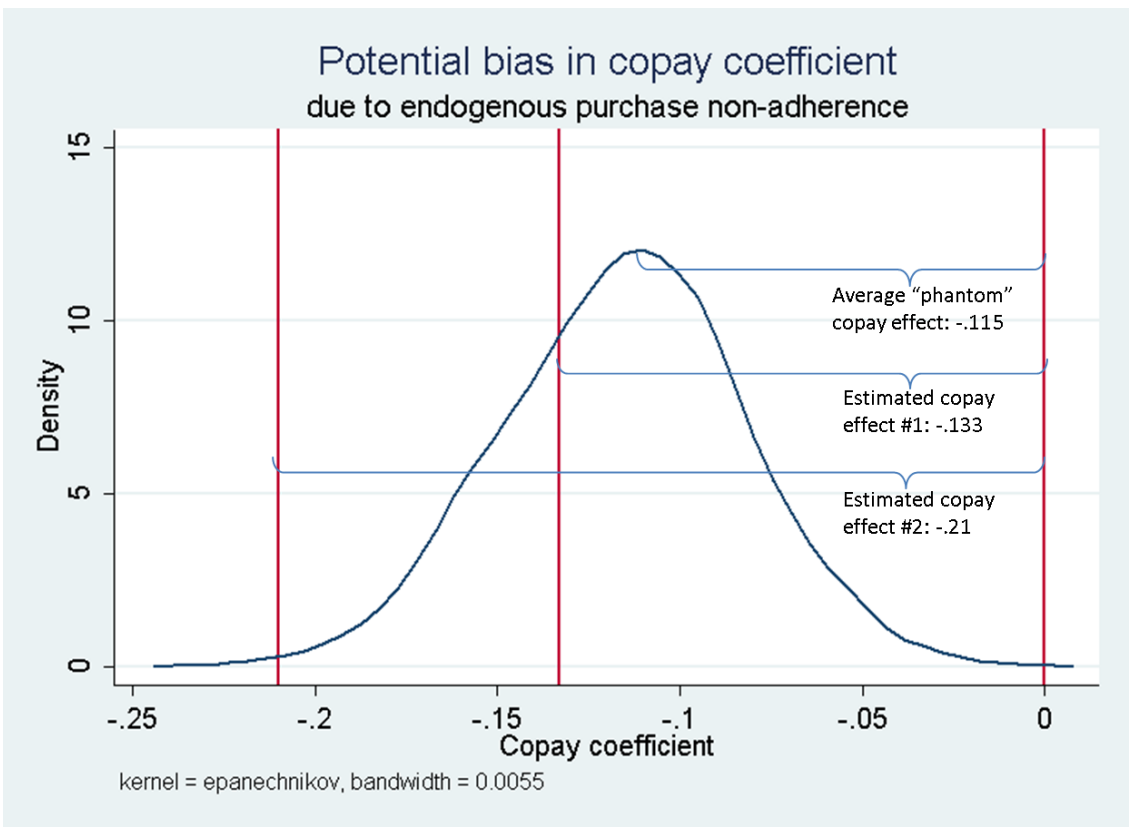

Figure 10: Potential bias in copay coefficient. The distribution of the estimated copay coefficient in 5,000 simulations in which prescriptions are assigned at random but copays influence the probability that a written prescription is filled, and therefore, observed. Copay effect \#1 is estimated using observed prescriptions prior to the expiration of Zocor's patent. Copay effect \#2 is estimated in our entire copay-verified sample, 2005-2007. 
Table 3: Descriptive Statistics (Verified Copay Sample)

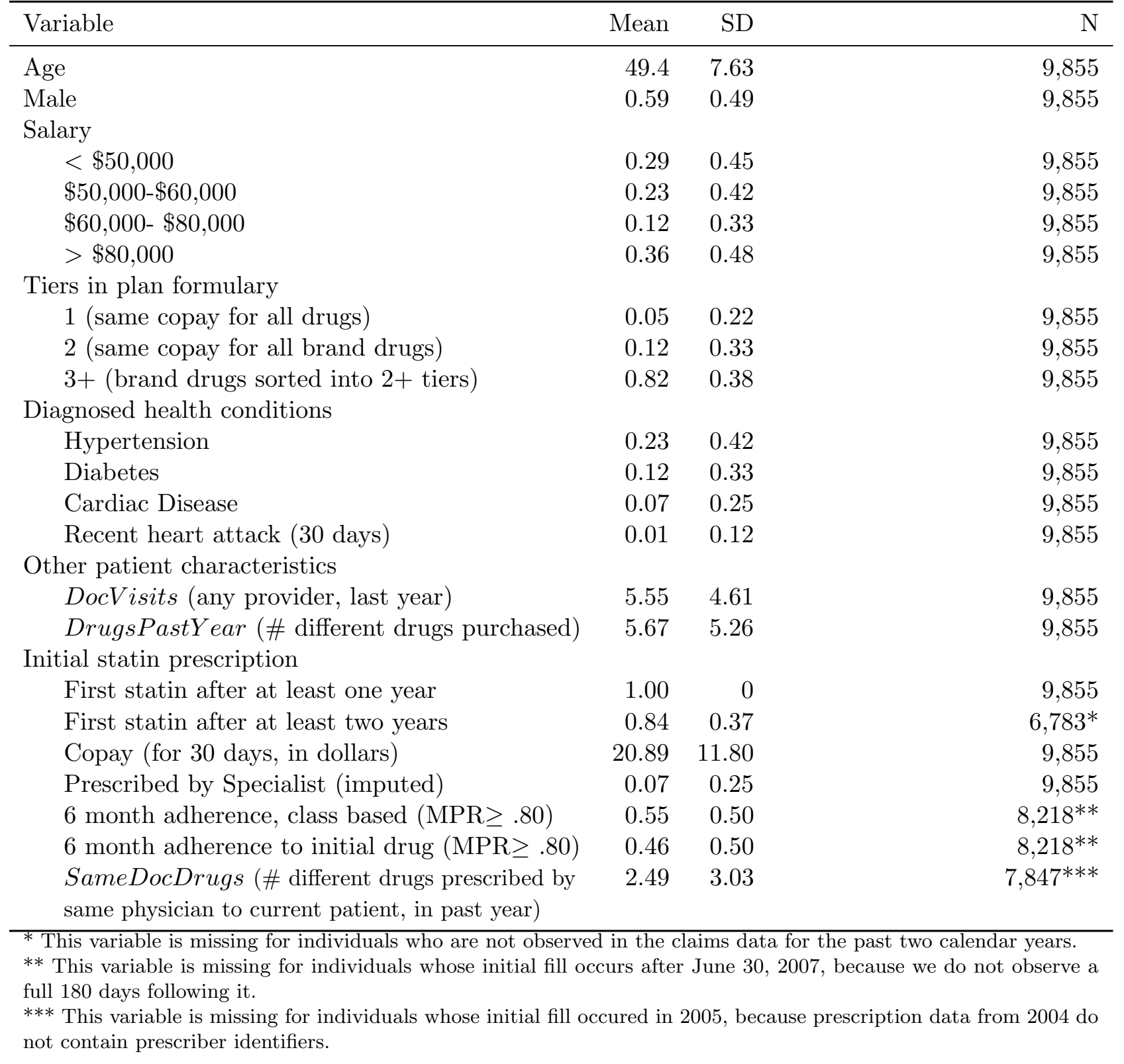


Table 4: Copay effects on initial prescription, prior to Zocor's patent expiration

\begin{tabular}{|c|c|c|c|c|c|c|}
\hline Copay-verified sample & (1) & $(2)$ & $(3)$ & $(4)$ & $(5)$ & (6) \\
\hline$p_{j t}($ Copay, in $\$ 10)$ & $\begin{array}{c}-0.12^{* *} \\
(0.05)\end{array}$ & $\begin{array}{c}-0.13^{* *} \\
(0.05)\end{array}$ & $\begin{array}{c}-0.14^{* * *} \\
(0.05)\end{array}$ & $\begin{array}{c}-0.11^{* *} \\
(0.05)\end{array}$ & $\begin{array}{c}-0.12^{* *} \\
(0.05)\end{array}$ & $\begin{array}{c}-0.13^{* *} \\
(0.05)\end{array}$ \\
\hline x High Salary & $\begin{array}{l}-0.059 \\
(0.06)\end{array}$ & $\begin{array}{l}-0.034 \\
(0.07)\end{array}$ & $\begin{array}{l}-0.017 \\
(0.07)\end{array}$ & $\begin{array}{l}-0.053 \\
(0.06)\end{array}$ & $\begin{array}{l}-0.024 \\
(0.07)\end{array}$ & $\begin{array}{c}-0.00053 \\
(0.07)\end{array}$ \\
\hline Doctor's last prescription & & $\begin{array}{c}0.60^{* * *} \\
(0.06)\end{array}$ & $\begin{array}{c}0.59^{* * *} \\
(0.06)\end{array}$ & & $\begin{array}{c}0.61^{* * *} \\
(0.06)\end{array}$ & $\begin{array}{c}0.61^{* * *} \\
(0.06)\end{array}$ \\
\hline Patient's last prescription & & $\begin{array}{c}1.27^{* * *} \\
(0.1)\end{array}$ & $\begin{array}{c}1.27^{* * *} \\
(0.1)\end{array}$ & & $\begin{array}{c}1.29^{* * *} \\
(0.1)\end{array}$ & $\begin{array}{c}1.29^{* * *} \\
(0.1)\end{array}$ \\
\hline \multicolumn{7}{|l|}{ Choice of Lipitor } \\
\hline High salary & & & $\begin{array}{c}-0.074 \\
(0.1)\end{array}$ & & & $\begin{array}{c}-0.0089 \\
(0.1)\end{array}$ \\
\hline Monthly time trend & & & & $\begin{array}{c}-0.064^{* * *} \\
(0.010)\end{array}$ & $\begin{array}{c}-0.067^{* * *} \\
(0.010)\end{array}$ & $\begin{array}{c}-0.067^{* * *} \\
(0.010)\end{array}$ \\
\hline \multicolumn{7}{|l|}{ Choice of Pravachol } \\
\hline High salary & & & $\begin{array}{l}-0.29 \\
(0.2)\end{array}$ & & & $\begin{array}{l}-0.21 \\
(0.2)\end{array}$ \\
\hline Monthly time trend & & & & $\begin{array}{c}-0.090^{* * *} \\
(0.02)\end{array}$ & $\begin{array}{c}-0.081^{* * *} \\
(0.02)\end{array}$ & $\begin{array}{c}-0.080^{* * *} \\
(0.02)\end{array}$ \\
\hline \multicolumn{7}{|l|}{ Choice of Zocor } \\
\hline High salary & & & $\begin{array}{c}-0.087 \\
(0.1)\end{array}$ & & & $\begin{array}{c}-0.070 \\
(0.1)\end{array}$ \\
\hline Monthly time trend & & & & $\begin{array}{c}-0.024^{* *} \\
(0.01)\end{array}$ & $\begin{array}{l}-0.017 \\
(0.01)\end{array}$ & $\begin{array}{l}-0.017 \\
(0.01)\end{array}$ \\
\hline \multicolumn{7}{|l|}{ Choice of Vytorin } \\
\hline High salary & & & $\begin{array}{c}0.068 \\
(0.1)\end{array}$ & & & $\begin{array}{l}0.11 \\
(0.1)\end{array}$ \\
\hline Monthly time trend & & & & $\begin{array}{c}-0.038^{* * *} \\
(0.01)\end{array}$ & $\begin{array}{c}-0.036^{* * *} \\
(0.01)\end{array}$ & $\begin{array}{c}-0.036^{* * *} \\
(0.01)\end{array}$ \\
\hline $\begin{array}{l}\mathrm{N} \\
\text { Log. Lik. } \\
\text { Patient characteristics } \\
\text { Drug-specific time trend } \\
\text { Salary-specific drug intercepts }\end{array}$ & $\begin{array}{c}4061 \\
-5262.84\end{array}$ & $\begin{array}{c}4061 \\
-5095.27 \\
\text { Yes }\end{array}$ & $\begin{array}{c}4061 \\
-5093.40 \\
\text { Yes } \\
\text { Yes }\end{array}$ & $\begin{array}{c}4061 \\
-5231.25 \\
\\
\text { Yes }\end{array}$ & $\begin{array}{c}4061 \\
-5059.72 \\
\text { Yes } \\
\text { Yes }\end{array}$ & $\begin{array}{c}4061 \\
-5058.24 \\
\text { Yes } \\
\text { Yes } \\
\text { Yes }\end{array}$ \\
\hline \multicolumn{7}{|c|}{ Average percent change in Zocor prescribing share expected from a $\$ 10$ ( $35 \%)$ copay increase } \\
\hline $\begin{array}{l}\text { Low salary patients } \\
\text { High salary patients }\end{array}$ & $\begin{array}{l}-0.10 \\
(0.00) \\
-0.15 \\
(0.00) \\
\end{array}$ & $\begin{array}{l}-0.11 \\
(0.01) \\
-0.14 \\
(0.01) \\
\end{array}$ & $\begin{array}{l}-0.12 \\
(0.01) \\
-0.13 \\
(0.01) \\
\end{array}$ & $\begin{array}{l}-0.09 \\
(0.00) \\
-0.14 \\
(0.00) \\
\end{array}$ & $\begin{array}{l}-0.10 \\
(0.01) \\
-0.12 \\
(0.01) \\
\end{array}$ & $\begin{array}{l}-0.11 \\
(0.01) \\
-0.11 \\
(0.01) \\
\end{array}$ \\
\hline
\end{tabular}

Conditional logit coefficients. Standard errors in parentheses.

These models estimate how the characteristics of drugs in the physician's choice set affect their probability of being individual $i$ 's first statin prescription fill in the period from January 2005 to June 2006. The choice set contains the five statin drugs that can achieve a level of LDL cholesterol reduction between $34 \%$ and $52 \%$. $p_{i j t}$ is the monthly copayment that applies to patient $i$ for drug $j$ at the time of prescribing, in units of ten dollars. Other patient characteristics included as controls are diagnosed health conditions, age decile, gender, and whether the drug was prescribed by a cardiac specialist, all of which are allowed to affect each drug's intercept separately. 
Table 5: Copay effects on initial prescription

\begin{tabular}{|c|c|c|c|c|}
\hline Copay-verified sample & $(1)$ & $(2)$ & $(3)$ & $(4)$ \\
\hline $\bar{p}_{j t}$ (National average copay) & $\begin{array}{c}-0.72^{* * *} \\
(0.05)\end{array}$ & $\begin{array}{c}-0.54^{* * *} \\
(0.08)\end{array}$ & $\begin{array}{c}-0.64^{* * *} \\
(0.06)\end{array}$ & $\begin{array}{c}-0.42^{* * *} \\
(0.08)\end{array}$ \\
\hline x High Salary & $\begin{array}{c}0.31^{* * *} \\
(0.05)\end{array}$ & $\begin{array}{c}0.31^{* * *} \\
(0.05)\end{array}$ & $\begin{array}{c}0.21^{* * *} \\
(0.05)\end{array}$ & $\begin{array}{c}0.20^{* * *} \\
(0.05)\end{array}$ \\
\hline$p_{i j t}-\bar{p}_{j t}($ Difference $)$ & $\begin{array}{c}-0.19^{* * *} \\
(0.04)\end{array}$ & $\begin{array}{c}-0.17^{* * *} \\
(0.04)\end{array}$ & $\begin{array}{c}-0.20^{* * *} \\
(0.05)\end{array}$ & $\begin{array}{c}-0.13^{* * *} \\
(0.05)\end{array}$ \\
\hline x High Salary & $\begin{array}{c}-0.075^{*} \\
(0.04)\end{array}$ & $\begin{array}{c}-0.076^{*} \\
(0.04)\end{array}$ & $\begin{array}{l}0.0080 \\
(0.05)\end{array}$ & $\begin{array}{l}0.016 \\
(0.05)\end{array}$ \\
\hline Doctor's last prescription & $\begin{array}{c}0.60^{* * *} \\
(0.03)\end{array}$ & $\begin{array}{c}0.60^{* * *} \\
(0.03)\end{array}$ & $\begin{array}{c}0.57^{* * *} \\
(0.03)\end{array}$ & $\begin{array}{c}0.57^{* * *} \\
(0.03)\end{array}$ \\
\hline Patient's last prescription & $\begin{array}{c}1.27^{* * *} \\
(0.05) \\
\end{array}$ & $\begin{array}{c}1.29^{* * *} \\
(0.06)\end{array}$ & $\begin{array}{c}1.25^{* * *} \\
(0.06)\end{array}$ & $\begin{array}{c}1.29^{* * *} \\
(0.06) \\
\end{array}$ \\
\hline $\begin{array}{l}\text { N } \\
\text { Log. Lik. } \\
\text { Patient characteristics } \\
\text { Drug-specific time trend } \\
\text { Plan-specific drug intercepts }\end{array}$ & $\begin{array}{c}9855 \\
-12726.68 \\
\text { Yes }\end{array}$ & $\begin{array}{c}9855 \\
-12681.81 \\
\text { Yes } \\
\text { Yes }\end{array}$ & $\begin{array}{c}9855 \\
-12350.18 \\
\text { Yes } \\
\\
\text { Yes }\end{array}$ & $\begin{array}{c}9855 \\
-12270.10 \\
\text { Yes } \\
\text { Yes } \\
\text { Yes }\end{array}$ \\
\hline \multicolumn{5}{|c|}{ Average percent change in Zocor prescribing share expected from a $\$ 10$ ( 35\%) copay increase } \\
\hline Low salary patients & $\begin{array}{l}-0.60 \\
(0.05)\end{array}$ & $\begin{array}{l}-0.46 \\
(0.04)\end{array}$ & $\begin{array}{l}-0.53 \\
(0.05)\end{array}$ & $\begin{array}{l}-0.35 \\
(0.03)\end{array}$ \\
\hline High salary patients & $\begin{array}{l}-0.35 \\
(0.03)\end{array}$ & $\begin{array}{l}-0.19 \\
(0.02)\end{array}$ & $\begin{array}{l}-0.37 \\
(0.03)\end{array}$ & $\begin{array}{l}-0.19 \\
(0.02)\end{array}$ \\
\hline $\begin{array}{l}\text { Estimates of } \lambda=\beta_{p_{i j t}-\bar{p}_{j t}} / \beta_{\bar{p}_{j t}} \\
\lambda_{L S} \text { (Low salary patients) }\end{array}$ & $\begin{array}{c}0.27 \\
(0.00)\end{array}$ & $\begin{array}{c}0.31 \\
(0.01)\end{array}$ & $\begin{array}{c}0.31 \\
(0.01)\end{array}$ & $\begin{array}{c}0.30 \\
(0.02)\end{array}$ \\
\hline$\lambda_{H S}$ (High salary patients) & $\begin{array}{c}0.65 \\
(0.01)\end{array}$ & $\begin{array}{c}1.07 \\
(0.12)\end{array}$ & $\begin{array}{c}0.44 \\
(0.01)\end{array}$ & $\begin{array}{c}0.49 \\
(0.05)\end{array}$ \\
\hline
\end{tabular}

Conditional logit coefficients. Standard errors in parentheses.

These models estimate how the characteristics of drugs in the physician's choice set affect their probability of being individual $i$ 's first statin prescription fill. The choice set contains the five statin drugs that can achieve a level of LDL cholesterol reduction between $34 \%$ and $52 \%$. $p_{i j t}$ is the monthly copayment that applies to patient $i$ for drug $j$ at the time of prescribing, in units of ten dollars. $\bar{p}_{j t}$ is the national average copay in year $t$ among employer-insured plans for either brand or generic drugs, from Kaiser Family Foundation [2007], depending on drug $j$ 's patent or off-patent status at time $t$. $\lambda$ is described in Section 4 as a measure of how well plan-specific copays are observed at the time of prescribing. 
Table 6: Copay effects on initial prescription, by previous prescribing in patient/physician pair

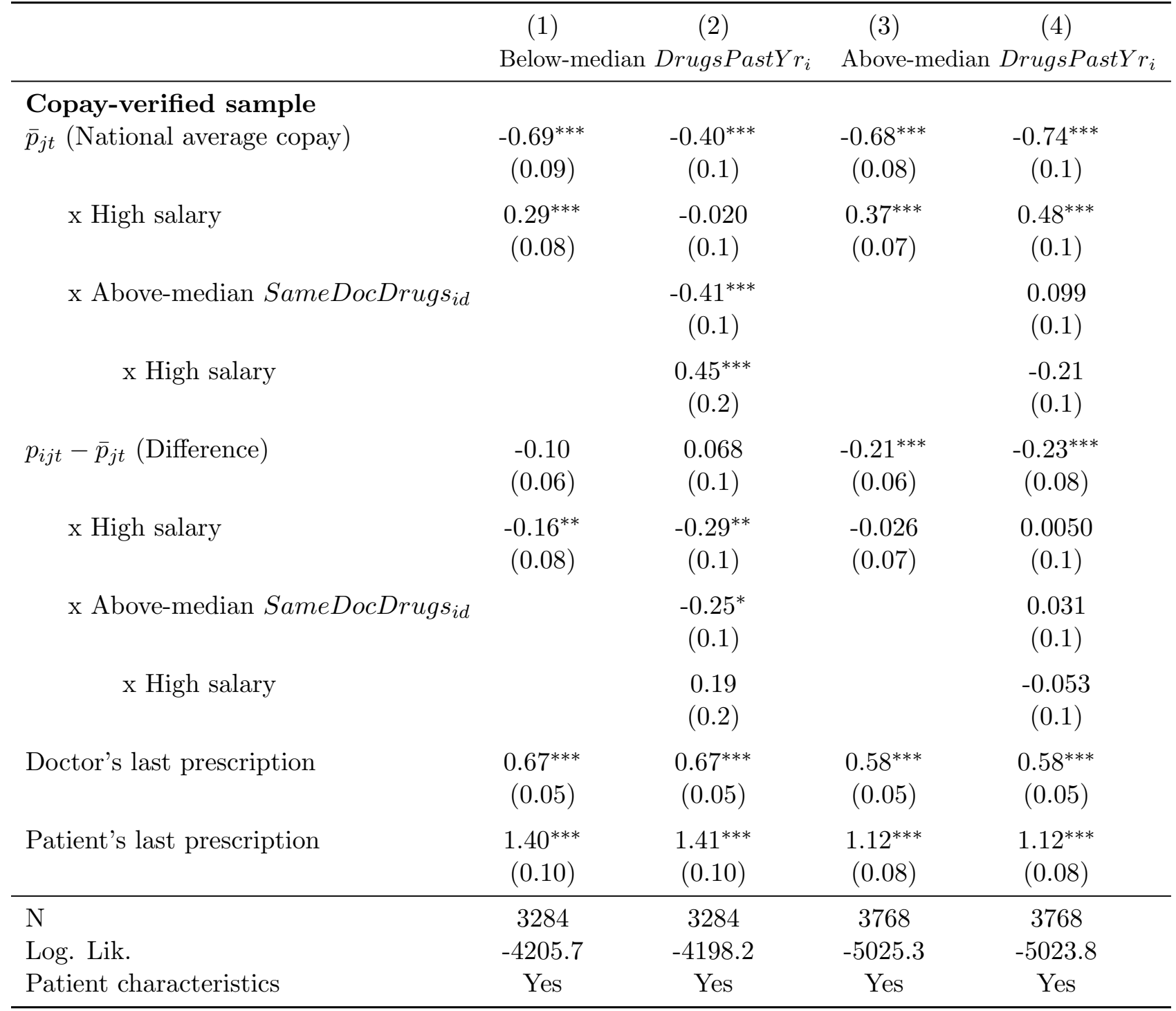

Conditional logit coefficients. Standard errors in parentheses.

These models build on the specification in column (1) of Table 5. The copay variables are interacted with a dummy indicating an above-median value of SameDocDrugs $s_{i d}$, which is the number of different drugs prescribed by physician $d$ to patient $i$ in the previous 365 days. We also divide the sample along DrugsPast $Y r_{i}$, the number of different drugs taken by a patient in the previous 365 days, which has a median value of 5 . In the group with below-median (above-median) values of DrugsPastY $r_{i}$, the median value of SameDocDrugs $i d$ is 1 (4). The sample includes 2006 and 2007 observations from the Copay Verified Sample, since physician identifiers are not included in 2004 data. We also exclude patients who took no drugs in the past year, since their value of SameDocDrugs $s_{i j}$ would be zero by necessity. 
Table 7: Copay effect on 6-month Adherence, prior to Zocor's patent expiration

\begin{tabular}{|c|c|c|c|c|}
\hline Panel A & (1) & $(2)$ & $(3)$ & (4) \\
\hline Copay (in $\$ 10$ ) & $\begin{array}{c}-0.050^{* * *} \\
(0.02)\end{array}$ & $\begin{array}{c}-0.050^{* * *} \\
(0.02)\end{array}$ & $\begin{array}{c}-0.038^{* * *} \\
(0.01)\end{array}$ & $\begin{array}{l}-0.040^{* * *} \\
\quad(0.01)\end{array}$ \\
\hline x High Salary & $\begin{array}{l}0.028^{*} \\
(0.01)\end{array}$ & $\begin{array}{l}0.027^{*} \\
(0.01)\end{array}$ & $\begin{array}{c}0.035^{* * *} \\
(0.01)\end{array}$ & $\begin{array}{c}0.036^{* * *} \\
(0.01)\end{array}$ \\
\hline Observations & 11431 & 11431 & 11431 & 11338 \\
\hline Patient characteristics & Yes & Yes & Yes & Yes \\
\hline Molecule f.e. & & Yes & Yes & Yes \\
\hline Plan f.e. & & & Yes & Yes \\
\hline Plan x Mol. f.e. & & & & Yes \\
\hline Panel B & $(5)$ & $(6)$ & $(7)$ & $(8)$ \\
\hline Copay (in $\$ 10$ ) & $\begin{array}{c}-0.038^{* * *} \\
(0.01)\end{array}$ & $\begin{array}{c}-0.037^{* * *} \\
(0.01)\end{array}$ & $\begin{array}{c}-0.036^{* * *} \\
(0.01)\end{array}$ & $\begin{array}{c}-0.041^{* * *} \\
\quad(0.01)\end{array}$ \\
\hline x High salary & $\begin{array}{c}0.036^{* * *} \\
(0.01)\end{array}$ & $\begin{array}{c}0.034^{* * *} \\
(0.01)\end{array}$ & $\begin{array}{c}0.031^{* * *} \\
(0.01)\end{array}$ & $\begin{array}{c}0.035^{* * *} \\
(0.01)\end{array}$ \\
\hline SameDoc (Above-median SameDocDrugs $i d$ ) & & & $\begin{array}{c}-0.0090 \\
(0.01)\end{array}$ & $\begin{array}{r}-0.021 \\
(0.02)\end{array}$ \\
\hline Above-median DrugsPast $Y r_{i}$ & & & $\begin{array}{r}-0.015 \\
(0.02)\end{array}$ & $\begin{array}{l}-0.015 \\
(0.02)\end{array}$ \\
\hline x SameDoc & & & $\begin{array}{l}0.016 \\
(0.02)\end{array}$ & $\begin{array}{l}0.015 \\
(0.02)\end{array}$ \\
\hline Copay x SameDoc & & & & $\begin{array}{c}0.011 \\
(0.008)\end{array}$ \\
\hline x High salary & & & & $\begin{array}{r}-0.0080 \\
(0.007)\end{array}$ \\
\hline $\begin{array}{l}\text { Observations } \\
\text { Patient characteristics } \\
\text { Molecule f.e. } \\
\text { Plan f.e. } \\
\text { Plan x Mol. f.e. }\end{array}$ & $\begin{array}{c}11431 \\
\text { Yes } \\
\text { Yes } \\
\text { Yes }\end{array}$ & $\begin{array}{c}11431 \\
\text { Yes } \\
\text { Yes } \\
\text { Yes }\end{array}$ & $\begin{array}{c}10218 \\
\text { Yes } \\
\text { Yes } \\
\text { Yes }\end{array}$ & $\begin{array}{c}10218 \\
\text { Yes } \\
\text { Yes } \\
\text { Yes }\end{array}$ \\
\hline $\begin{array}{l}\text { Added variables } \\
\text { Wald Test: Prob > chi-squared }\end{array}$ & $\begin{array}{c}\text { High sal. x Mol. } \\
0.98\end{array}$ & $\begin{array}{c}\text { Diag. x Mol. } \\
0.17\end{array}$ & $\begin{array}{c}- \\
0.74\end{array}$ & $\begin{array}{c}- \\
0.57\end{array}$ \\
\hline
\end{tabular}

Marginal effects; Standard errors in parentheses, clustered by plan. ${ }^{*} p<0.10,{ }^{* *} p<0.05,{ }^{* * *} p<0.01$

Note: Average marginal effect of a $\$ 10$ copay increase on the probability of Six month adherence (80\% or greater days supplied) is shown. High salary is above $\$ 50,000$, and $59.2 \%$ of this group is adherent. The omitted category is salary below $\$ 50,000$, of whom $46.6 \%$ are adherent. Patient characteristics include dummies for chronic conditions diagnosed, Prescription from a specialist, a 90-day first fill, previous statin usage (more than 365 days ago), age decile, sex, and salary group. In Panel B, we test the inclusion of additional variables: allowing high salary patients and patients with diagnosed conditions to respond differently to the drug prescribed (in (5) and (6)) and testing for differences in adherence based on patients' recent experience with their plan formularies and with the current prescriber (in (7) and (8)). 
Table 8: Predicted Adherence Probabilities (average)

\begin{tabular}{rcccc}
\hline & $\min _{j \in J} q_{i j}$ & $\begin{array}{c}q_{i j}, j=\text { drug prescribed } \\
\text { (status quo) }\end{array}$ & $\max _{j \in J} q_{i j}$ & $\begin{array}{c}\text { Max. potential improvement } \\
\text { relative to status quo }\end{array}$ \\
\hline Low salary patients & & & & \\
Inexperienced & 0.44 & 0.48 & 0.53 & 0.05 \\
Experienced & 0.41 & 0.44 & 0.48 & 0.03 \\
High salary patients & & & & 0.01 \\
Inexperienced & 0.56 & 0.57 & 0.58 & 0.01 \\
Experienced & 0.57 & 0.57 & 0.58 & \\
\hline
\end{tabular}

Table 9: Monthly Copays (average)

\begin{tabular}{cccc}
\hline & $p_{i j}, j=$ drug prescribed & $p_{i j}, j=\operatorname{argmax}\left(q_{i j}\right)$ & $\min _{j \in J}\left(p_{i j}\right)$, \\
\hline Low salary patients & & & \\
\hline Inexperienced & $\$ 23.30$ & $\$ 13.73$ & $\$ 13.54$ \\
Experienced & $\$ 21.62$ & $\$ 13.12$ & $\$ 12.94$ \\
High salary patients & & & \\
Inexperienced & $\$ 18.99$ & $\$ 25.09$ & $\$ 10.77$ \\
Experienced & $\$ 19.08$ & $\$ 10.59$ & $\$ 10.45$ \\
\hline
\end{tabular}

Table 10: Changes under simulated counterfactuals

\begin{tabular}{|c|c|c|c|c|}
\hline & $\begin{array}{l}\text { Rx that change } \\
\quad\left(j^{\prime} \neq j\right)\end{array}$ & $\begin{array}{l}\text { Change } \\
\left(\Delta q_{i j}\right)\end{array}$ & $\begin{array}{c}n \text { adherence rate } \\
\text { (Share of max.) }\end{array}$ & $\begin{array}{c}\text { Copay change } \\
\left(\Delta p_{i j}\right)\end{array}$ \\
\hline \multicolumn{5}{|l|}{ Low salary patients } \\
\hline Inexperienced & $9 \%$ & 0.007 & 0.15 & $-\$ 1.63$ \\
\hline Experienced & $7 \%$ & 0.004 & 0.12 & $-\$ 1.10$ \\
\hline \multicolumn{5}{|l|}{$\underline{\text { High salary patients }}$} \\
\hline Inexperienced & $2 \%$ & 0.000 & 0.00 & $-\$ 0.28$ \\
\hline Experienced & $2 \%$ & 0.000 & 0.02 & $-\$ 0.26$ \\
\hline \multicolumn{5}{|c|}{ 2. Prescriber observes copays and has patient-specific experience } \\
\hline & $\begin{array}{l}\text { Rx that change } \\
\quad\left(j^{\prime} \neq j\right)\end{array}$ & $\begin{array}{l}\text { Change } \\
\left(\Delta q_{i j}\right)\end{array}$ & $\begin{array}{r}\text { n adherence rate } \\
\text { (Share of max.) }\end{array}$ & $\begin{array}{c}\text { Copay change } \\
\left(\Delta p_{i j}\right)\end{array}$ \\
\hline \multicolumn{5}{|l|}{ Low salary patients } \\
\hline Inexperienced & $14 \%$ & 0.011 & 0.24 & $-\$ 2.66$ \\
\hline Experienced & $6 \%$ & 0.003 & 0.09 & $-\$ 0.88$ \\
\hline \multicolumn{5}{|l|}{ High salary patients } \\
\hline Inexperienced & $2 \%$ & 0.000 & 0.00 & $-\$ 0.23$ \\
\hline Experienced & $3 \%$ & 0.000 & 0.03 & $-\$ 0.52$ \\
\hline
\end{tabular}

3. The drug with the lowest copay is always prescribed.

\begin{tabular}{|c|c|c|c|c|}
\hline & $\begin{array}{l}\text { Rx that change } \\
\quad\left(j^{\prime} \neq j\right)\end{array}$ & $\begin{array}{l}\text { Change } \\
\left(\Delta q_{i j}\right)\end{array}$ & $\begin{array}{l}\text { in adherence rate } \\
\text { (Share of max.) }\end{array}$ & $\begin{array}{c}\text { Copay change } \\
\left(\Delta p_{i j}\right)\end{array}$ \\
\hline \multicolumn{5}{|l|}{ Low salary patients } \\
\hline Inexperienced & $55 \%$ & 0.044 & 0.94 & $-\$ 9.76$ \\
\hline Experienced & $54 \%$ & 0.032 & 0.94 & $-\$ 8.68$ \\
\hline \multicolumn{5}{|l|}{ High salary patients } \\
\hline Inexperienced & $49 \%$ & 0.004 & 0.36 & $-\$ 8.21$ \\
\hline Experienced & $53 \%$ & 0.007 & 0.75 & $-\$ 8.63$ \\
\hline
\end{tabular}

Simulations described in Section 5.5. 
Table 11: Does patient salary affect the probability of receiving a low-cost prescription?

(1)

Post-expiry of Zocor patent $Y=$ Off-patent drug prescribed
(3)

(4)

Pre-expiry of Zocor patent

$Y=$ Tier 2 drug prescribed

\begin{tabular}{lcccc}
\hline High salary & $\begin{array}{c}-0.048^{* * *} \\
(0.01)\end{array}$ & $\begin{array}{c}-0.081^{* * *} \\
(0.02)\end{array}$ & $\begin{array}{c}-0.0054 \\
(0.01)\end{array}$ & $\begin{array}{c}-0.024 \\
(0.04)\end{array}$ \\
\hline Overall share of $Y=1$ & 0.41 & 0.41 & 0.55 & 0.55 \\
\hline Observations & 10665 & 10665 & 6842 & 6842 \\
Patient characteristics & & & Yes & Yes \\
Plan f.e. & Yes & Yes & Yes & Yes \\
Prescriber f.e. & & Yes & & Yes
\end{tabular}

The linear probability model allows us to include both plan and prescriber fixed effects. The sample is limited to plans with three or more tiers for consistency between columns (1)-(2) and (3)-(4). The Zocor patent expired in June 2006, the midpoint of our sample time period. The sample size is larger in the post-expiry period, however, because of a large increase in the number of firms reported in the data. Clustered standard errors in parentheses. 
Table 12: Generic prescribing, by previous prescribing in patient/physician pair

\begin{tabular}{|c|c|c|c|c|c|c|}
\hline & \multirow{2}{*}{\multicolumn{3}{|c|}{$\begin{array}{ccc}(1) & (2) & (3) \\
\text { Below-median } & \text { DrugsPastYr }\end{array}$}} & \multirow{2}{*}{\multicolumn{3}{|c|}{$\begin{array}{ccc}(4) & (5) \\
\text { Above-median } & (6) \\
\text { DrugsPastYr } & \end{array}$}} \\
\hline & & & & & & \\
\hline High salary & $\begin{array}{l}-0.025 \\
(0.02)\end{array}$ & $\begin{array}{l}0.020 \\
(0.03)\end{array}$ & $\begin{array}{l}0.061 \\
(0.04)\end{array}$ & $\begin{array}{c}-0.058^{* * *} \\
(0.01)\end{array}$ & $\begin{array}{c}-0.054^{* * *} \\
(0.02)\end{array}$ & $\begin{array}{c}-0.063^{* *} \\
(0.03)\end{array}$ \\
\hline Above-median SameDocDrugs $s_{i d}$ & $\begin{array}{l}0.0020 \\
(0.01)\end{array}$ & $\begin{array}{l}0.049^{*} \\
(0.03)\end{array}$ & $\begin{array}{l}0.046^{*} \\
(0.03)\end{array}$ & $\begin{array}{c}-0.0032 \\
(0.01)\end{array}$ & $\begin{array}{c}0.0023 \\
(0.02)\end{array}$ & $\begin{array}{c}0.0034 \\
(0.03)\end{array}$ \\
\hline x High salary & & $\begin{array}{c}-0.067^{* *} \\
(0.03)\end{array}$ & $\begin{array}{c}-0.061^{*} \\
(0.03)\end{array}$ & & $\begin{array}{c}-0.0083 \\
(0.03)\end{array}$ & $\begin{array}{c}-0.0098 \\
(0.03)\end{array}$ \\
\hline DrugsPastYr $r_{i}$ & $\begin{array}{r}-0.0049 \\
(0.006)\end{array}$ & $\begin{array}{r}-0.0048 \\
(0.006)\end{array}$ & $\begin{array}{r}0.0077 \\
(0.01)\end{array}$ & $\begin{array}{l}-0.0013 \\
(0.001)\end{array}$ & $\begin{array}{l}-0.0013 \\
(0.001)\end{array}$ & $\begin{array}{l}-0.0019 \\
(0.002)\end{array}$ \\
\hline x High salary & & & $\begin{array}{r}-0.017 \\
(0.01)\end{array}$ & & & $\begin{array}{r}0.00097 \\
(0.002)\end{array}$ \\
\hline Prescribed by specialist & $\begin{array}{c}-0.096^{* * *} \\
(0.03)\end{array}$ & $\begin{array}{c}-0.097^{* * *} \\
(0.03)\end{array}$ & $\begin{array}{c}-0.091^{*} \\
(0.05)\end{array}$ & $\begin{array}{c}-0.072^{* * *} \\
(0.02)\end{array}$ & $\begin{array}{c}-0.072^{* * *} \\
(0.02)\end{array}$ & $\begin{array}{c}-0.073^{* *} \\
(0.03)\end{array}$ \\
\hline x High salary & & & $\begin{array}{c}-0.0075 \\
(0.05)\end{array}$ & & & $\begin{array}{c}0.0014 \\
(0.04)\end{array}$ \\
\hline Observations & 6567 & 6567 & 6567 & 8008 & 8008 & 8008 \\
\hline Patient characteristics & Yes & Yes & Yes & Yes & Yes & Yes \\
\hline Plan f.e. & Yes & Yes & Yes & Yes & Yes & Yes \\
\hline
\end{tabular}

Linear probability model. Clustered standard errors in parentheses.

DrugsPastY $r_{i}$, the number of different drugs taken by a patient in the previous 365 days, has a median value of 5. The High salary dummy is interacted with a dummy indicating an above-median value of SameDocDrugs $s_{i d}$, which is the number of different drugs prescribed by physician $d$ to patient $i$ in the previous 365 days. In the group with below-median (above-median) values of DrugsPastYr $r_{i}$, the median value of SameDocDrugs $s_{i d}$ is 1 (4). The sample includes 2006 and 2007 observations from the entire sample (physician identifiers are not included in 2004 data). We also exclude patients who took no drugs in the past year, since their value of SameDocDrugs $s_{i j}$ would be zero by necessity. Other controls include the number of days in which the patient had at least one outpatient office visit in the past year, the share of a physician's observed prescriptions with above-median SameDocDrugs ${ }_{i d}$, and they usual set of patient characteristics. 


\section{Appendix}

1. Switching costs appear to be high.

It is a stylized fact that switching to a different statin is highly correlated with a long delay (or discontinuation) of statin treatment. Among patients who refilled the same drug they were initially prescribed, the median number of days between the first fill and the second fill was 34 (mean $=54, \mathrm{sd}=70)$, whereas for patients whose second fill was for a different drug, the median number of days in between was $105($ mean $=202, \mathrm{sd}=220) .{ }^{55}$. Sixty-five percent of patients who do not switch drugs between their first and second fills are adherent over the first six months, while only $9.6 \%$ of those who switch are adherent over the first six months. By the end of the six months following the initial fill, $15 \%$ of adherent patients are on a different statin than the one they initially started. This suggests that it might be easier to switch statins upon subsequent visits to the prescriber than between visits.

2. Description of Simulation Procedure used in Section 5.5.

We use an Accept-Reject approach to generate a set of Type I extreme value errors that rationalize each observed prescription, given their estimated values of indirect utility $V_{j}$. Draws of errors for each patient $i$ 's choice set are repeated until $\epsilon_{i j} \ldots \epsilon_{i J}$ are such that $U_{i j}=$ $X_{i j} B+\epsilon_{i j}>U_{i k}=X_{i k} B+\epsilon_{i k}$ for all unchosen drugs $k$. We then hold the set of generated errors $\left\{\epsilon_{i j} \ldots \epsilon_{i J}, \forall i\right\}$ constant in evaluating which drug would be chosen for each patient under the new values of $B$ implied by each counterfactual scenario.

3. The table below reports the "national average copays" of brand and generic drugs, for employer-insured patients, used in the analysis of Section 5.2, and how they compare to the average statin copays across the plans in each of our samples.

Table 13: Average Copay Comparison

\begin{tabular}{lccc}
\hline \multicolumn{4}{c}{ Panel A: Single-Source Brand Drugs } \\
& KFF Survey* & Full sample & Copay-Verified sample \\
\hline 2005 & $\$ 22.5$ & $\$ 21.08$ & $\$ 24.95$ \\
2006 & $\$ 24$ & $\$ 23.77$ & $\$ 24.38$ \\
2006 & $\$ 24$ & $\$ 23.63$ & $\$ 23.79$ \\
\hline
\end{tabular}

Panel B: Generic Drugs

\begin{tabular}{cccc} 
& KFF Survey* $^{*}$ & Full sample & Copay-Verified sample \\
\hline 2005 & $\$ 10$ & $\$ 9.81$ & $\$ 9.15$ \\
2006 & $\$ 11$ & $\$ 11.02$ & $\$ 11.44$ \\
2006 & $\$ 10.5$ & $\$ 8.45$ & $\$ 9.97$ \\
\hline
\end{tabular}

*These values were taken from Kaiser Family Foundation [2007], based on annual surveys of a random sample of U.S. employers.

These are the values we take to be a prescriber's expectation of brand and generic drug copays for an employer-insured patient, in Section 5.2

\footnotetext{
${ }^{55}$ To simplify interpretation, the numbers presented here correspond to patients whose first fill was a 30 -day prescription. Similar patterns exist for patients with 90-day first prescriptions
} 
TABLE 2. ATP III LDL-C Goals and Cutpoints for TLC and Drug Therapy in Different Risk Categories and Proposed Modifications Based on Recent Clinical Trial Evidence

\begin{tabular}{|c|c|c|c|}
\hline Risk Category & LDL-C Goal & Initiate TLC & Consider Drug Therapy** \\
\hline $\begin{array}{l}\text { High risk: } \mathrm{CHD}^{*} \text { or } \mathrm{CHD} \text { risk equivalents } \\
\text { (10-year risk }>20 \%)\end{array}$ & $\begin{array}{l}<100 \mathrm{mg} / \mathrm{dL} \\
\text { (optional goal: }<70 \mathrm{mg} / \mathrm{dL}) \|\end{array}$ & $\geq 100 \mathrm{mg} / \mathrm{dl} \#$ & $\begin{array}{l}\geq 100 \mathrm{mg} / \mathrm{dL}+\dagger \\
(<100 \mathrm{mg} / \mathrm{dL}: \text { consider drug options })^{\star \star}\end{array}$ \\
\hline $\begin{array}{l}\text { Moderately high risk: } 2+\text { risk factorsł } \\
\text { (10-year risk } 10 \% \text { to } 20 \%) \S \S\end{array}$ & $<130 \mathrm{mg} / \mathrm{dL} \mid$ & $\geq 130 \mathrm{mg} / \mathrm{dL} \#$ & $\begin{array}{l}\geq 130 \mathrm{mg} / \mathrm{dL} \\
\text { (100-129 mg/dL; consider drug options)\# }\end{array}$ \\
\hline $\begin{array}{l}\text { Moderate risk: } 2+\text { risk factorsł (10-year } \\
\text { risk }<10 \%) \S \S\end{array}$ & $<130 \mathrm{mg} / \mathrm{dL}$ & $\geq 130 \mathrm{mg} / \mathrm{dL}$ & $\geq 160 \mathrm{mg} / \mathrm{dL}$ \\
\hline Lower risk: 0-1 risk factor§ & $<160 \mathrm{mg} / \mathrm{dL}$ & $\geq 160 \mathrm{mg} / \mathrm{dL}$ & $\begin{array}{l}\geq 190 \mathrm{mg} / \mathrm{dL} \\
\text { (160-189 mg/dL: LDL-lowering drug optional) }\end{array}$ \\
\hline
\end{tabular}

${ }^{*} \mathrm{CHD}$ includes history of myocardial infarction, unstable angina, stable angina, coronary artery procedures (angioplasty or bypass surgery), or evidence of clinically significant myocardial ischemia.

tCHD risk equivalents include clinical manifestations of noncoronary forms of atherosclerotic disease (peripheral arterial disease, abdominal aortic aneurysm, and carotid artery disease [transient ischemic attacks or stroke of carotid origin or $>50 \%$ obstruction of a carotid artery]), diabetes, and $2+$ risk factors with 10 -year risk for hard $\mathrm{CHD}>20 \%$.

¥Risk factors include cigarette smoking, hypertension (BP $\geq 140 / 90 \mathrm{~mm} \mathrm{Hg}$ or on antihypertensive medication), low HDL cholesterol $(<40 \mathrm{mg} / \mathrm{dL}$ ), family history of premature $\mathrm{CHD}$ (CHD in male first-degree relative $<55$ years of age; $\mathrm{CHD}$ in female first-degree relative $<65$ years of age), and age (men $\geq 45$ years; women $\geq 55$ years).

$\S \S E l e c t r o n i c ~ 10-y e a r$ risk calculators are available at www.nhlbi.nih.gov/guidelines/cholesterol.

§Almost all people with zero or 1 risk factor have a 10-year risk $<10 \%$, and 10-year risk assessment in people with zero or 1 risk factor is thus not necessary. |Very high risk favors the optional LDL-C goal of $<70 \mathrm{mg} / \mathrm{dL}$, and in patients with high triglycerides, non-HDL-C $<100 \mathrm{mg} / \mathrm{dL}$. I0ptional LDL-C goal $<100 \mathrm{mg} / \mathrm{dL}$.

\#Any person at high risk or moderately high risk who has lifestyle-related risk factors (eg, obesity, physical inactivity, elevated triglyceride, low HDL-C, or metabolic syndrome) is a candidate for therapeutic lifestyle changes to modify these risk factors regardless of LDL-C level.

**When LDL-lowering drug therapy is employed, it is advised that intensity of therapy be sufficient to achieve at least a $30 \%$ to $40 \%$ reduction in LDL-C levels. ttIf baseline LDL-C is $<100 \mathrm{mg} / \mathrm{dL}$, institution of an LDL-lowering drug is a therapeutic option on the basis of available clinical trial results. If a high-risk person has high triglycerides or low HDL-C, combining a fibrate or nicotinic acid with an LDL-lowering drug can be considered.

\#FFor moderately high-risk persons, when LDL-C level is 100 to $129 \mathrm{mg} / \mathrm{dL}$, at baseline or on lifestyle therapy, initiation of an LDL-lowering drug to achieve an LDL-C level $<100 \mathrm{mg} / \mathrm{dL}$ is a therapeutic option on the basis of available clinical trial results.

Figure 11: This chart of goal LDL levels (from Grundy et al. [2004]) has been widely disseminated by the NIH's National Cholesterol Education Program and appears in the most commonly used physician pocket manual on prescription drugs, Tarascon Pocket Pharmacopoeia.

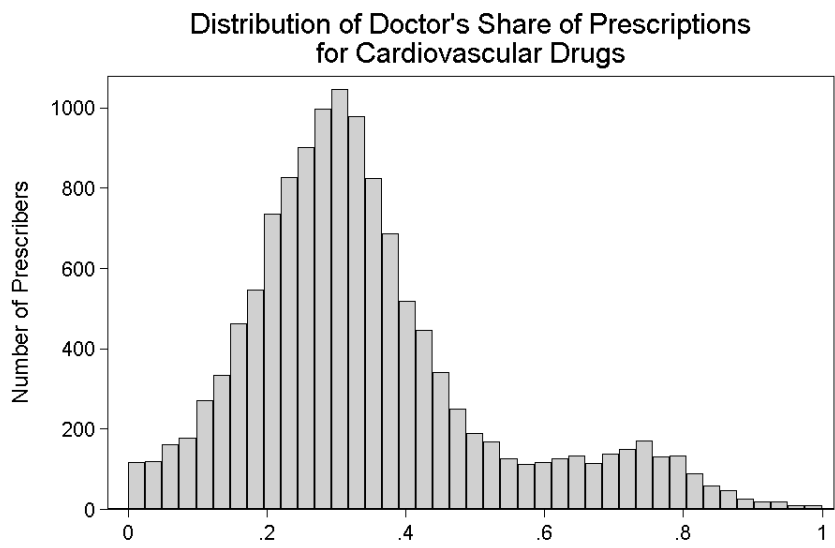

Figure 12: This figure shows the distribution of the share of prescriptions for cardiovascular drugs, by unique prescriber. We denote prescribers with shares above 0.60 as specialists. 
Table 14: Logit coefficients and exclusion tests, using Model 3 in Table 4.

\begin{tabular}{|c|c|c|c|c|c|}
\hline & $\begin{array}{c}(1) \\
\text { Lipitor }\end{array}$ & $\begin{array}{c}(2) \\
\text { Pravachol }\end{array}$ & $\begin{array}{c}(3) \\
\text { Vytorin }\end{array}$ & $\begin{array}{c}(4) \\
\text { Zocor }\end{array}$ & $\begin{array}{c}(5) \\
\text { Wald test p-value }\end{array}$ \\
\hline Prescribed by specialist & $\begin{array}{c}-0.040 \\
(0.2)\end{array}$ & $\begin{array}{l}-0.20 \\
(0.4)\end{array}$ & $\begin{array}{c}-0.47^{*} \\
(0.3)\end{array}$ & $\begin{array}{c}-0.54^{* *} \\
(0.3)\end{array}$ & 0.05 \\
\hline Age group dummies & & & & & 0.12 \\
\hline Age $40-49$ & $\begin{array}{c}0.030 \\
(0.2)\end{array}$ & $\begin{array}{l}0.39 \\
(0.4)\end{array}$ & $\begin{array}{l}0.23 \\
(0.2)\end{array}$ & $\begin{array}{c}0.031 \\
(0.2)\end{array}$ & \\
\hline Age 50-59 & $\begin{array}{l}0.20 \\
(0.2)\end{array}$ & $\begin{array}{c}0.93^{* *} \\
(0.4)\end{array}$ & $\begin{array}{c}0.38^{* *} \\
(0.2)\end{array}$ & $\begin{array}{c}0.31^{*} \\
(0.2)\end{array}$ & \\
\hline Age $60-65$ & $\begin{array}{l}0.13 \\
(0.2)\end{array}$ & $\begin{array}{c}1.29 * * * \\
(0.5)\end{array}$ & $\begin{array}{l}0.27 \\
(0.3)\end{array}$ & $\begin{array}{c}0.093 \\
(0.3)\end{array}$ & \\
\hline Male & $\begin{array}{r}-0.12 \\
(0.1)\end{array}$ & $\begin{array}{c}-0.45^{* *} \\
(0.2)\end{array}$ & $\begin{array}{l}-0.15 \\
(0.1)\end{array}$ & $\begin{array}{c}-0.21^{*} \\
(0.1)\end{array}$ & 0.19 \\
\hline High cholesterol & $\begin{array}{c}-0.35^{* * *} \\
(0.1)\end{array}$ & $\begin{array}{l}-0.28 \\
(0.3)\end{array}$ & $\begin{array}{l}0.16 \\
(0.1)\end{array}$ & $\begin{array}{c}-0.35^{* *} \\
(0.1)\end{array}$ & 0.00 \\
\hline Cardiac disease & $\begin{array}{c}0.050 \\
(0.2)\end{array}$ & $\begin{array}{l}-0.32 \\
(0.5)\end{array}$ & $\begin{array}{l}0.13 \\
(0.3)\end{array}$ & $\begin{array}{l}0.065 \\
(0.3)\end{array}$ & 0.93 \\
\hline Diabetes & $\begin{array}{c}-0.062 \\
(0.1)\end{array}$ & $\begin{array}{l}0.20 \\
(0.3)\end{array}$ & $\begin{array}{c}-0.092 \\
(0.2)\end{array}$ & $\begin{array}{r}0.077 \\
(0.2)\end{array}$ & 0.71 \\
\hline Hypertension & $\begin{array}{l}-0.15 \\
(0.1)\end{array}$ & $\begin{array}{l}-0.15 \\
(0.2)\end{array}$ & $\begin{array}{c}-0.035 \\
(0.1)\end{array}$ & $\begin{array}{c}-0.048 \\
(0.1)\end{array}$ & 0.65 \\
\hline AMI ever observed & $\begin{array}{l}0.82 \\
(1.1)\end{array}$ & $\begin{array}{l}1.87 \\
(1.5)\end{array}$ & $\begin{array}{l}1.11 \\
(1.2)\end{array}$ & $\begin{array}{l}0.14 \\
(1.4)\end{array}$ & 0.69 \\
\hline Recent AMI (past month) & $\begin{array}{c}-0.050 \\
(1.2)\end{array}$ & $\begin{array}{c}-0.079 \\
(1.6)\end{array}$ & $\begin{array}{l}-1.29 \\
(1.3)\end{array}$ & $\begin{array}{l}1.13 \\
(1.5)\end{array}$ & 0.43 \\
\hline Salary above $\$ 50,000$ & $\begin{array}{c}-0.074 \\
(0.1)\end{array}$ & $\begin{array}{l}-0.29 \\
(0.2)\end{array}$ & $\begin{array}{l}0.068 \\
(0.1)\end{array}$ & $\begin{array}{c}-0.087 \\
(0.1)\end{array}$ & 0.44 \\
\hline $\begin{array}{l}\text { Alternative-specific } \\
\text { constant }\end{array}$ & $\begin{array}{c}1.27 \\
(0.17)\end{array}$ & $\begin{array}{l}-1.66 \\
(0.42)\end{array}$ & $\begin{array}{c}-.16 \\
(0.22)\end{array}$ & $\begin{array}{c}0.21 \\
(0.21)\end{array}$ & $\mathrm{N} / \mathrm{A}$ \\
\hline
\end{tabular}

$\mathrm{N}=4061$. Excluded choice is Crestor. Columns (1)-(4) show the estimated coefficient of each dummy variable on the choice of each drug in the conditional logit regression from Table 6, Column (3). Column (5) shows the p-value of the Wald test statistic when testing for the exclusion of each variable or set of variables from the model. 